\title{
SALARIO Y CONDICIONES DE TRABAJO EN LA INDUSTRIA DE LA SEDA VALENCIANA DEL SIGLO XVIII ${ }^{1}$
}

\author{
Ricardo Franch Benavent \\ Universidad de Valencia
}

\begin{abstract}
Resumen. La modalidad de contratación de la mano de obra más habitual en la industria de la seda valenciana del siglo XVIII era la remuneración a destajo, por lo que el salario dependía del rendimiento y el ritmo de trabajo. El carácter estacional de la hilatura determinaba que su entidad fuese elevada, reduciéndose considerablemente al concentrarse la producción en establecimientos fabriles. El devanado era realizado a tiempo parcial por la mano de obra femenina bajo el control de los torcedores, con quienes los fabricantes acordaban la realización de ambas operaciones a destajo, lo que generó graves conflictos entre ambos colectivos. Los fabricantes encargaban también la realización del tejido a los artesanos, precisándose en las ordenanzas gremiales la remuneración que debían percibir tanto los maestros como los oficiales por cada vara confeccionada. Pero la diversidad de los modelos elaborados y el tiempo desigual que requería su producción dificultan el conocimiento del salario finalmente obtenido.
\end{abstract} Palabras clave: trabajo a destajo, industria de la seda, industria rural, artesano, siglo XVIII.

Abstract. The most common work contract in the Valencian silk industry in the eighteenth century was by piecework, so that wages depended on the yield and rhythm of work. The seasonal nature of the spinning process determined high wages, but they were reduced by concentrating production in manufacturing establishments. The winding process was performed by part-time women workers controlled by the twisters, with whom the manufacturers agreed to carry out both processes by piecework, which created serious conflicts between the two groups. Manufacturers also ordered the textile production to masters and officers craftsmen, whose wages for

Recibido: 09-12-2013 · Aceptado: 03-10-2014 • Ricardo.Franch@uv.es

El presente trabajo se inserta en el marco del proyecto «Nuevas perspectivas de historia social en los territorios hispánicos del Mediterráneo occidental en la Edad Moderna» (HAR2014-53298-C21-P), financiado por el Ministerio de Economía y Competitividad. 
each rod were determined by the guild ordinances. However, the diversity of the confectioned models and the variety of times required makes it difficult to determine the final wages earned. Keywords: piecework, silk industry, rural industry, craftsman, Eighteenth century.

A pesar de su importancia como indicador de las condiciones sociales y económicas de la población del Antiguo Régimen, el estudio de los salarios se halla dificultado por la localización de las fuentes adecuadas para la obtención de información sobre actividades laborales que puedan considerarse representativas de la sociedad de la época. El recurso más habitual ha sido la utilización de la documentación generada por instituciones benéficas, religiosas o civiles, lo que ha determinado que la mayoría de las series disponibles correspondan a los oficios relacionados con el sector de la construcción y los servicios, tanto a nivel europeo (Van Zanden, 1999; Allen, 2001; Chor, 2005) como español (Hamilton, 1975 y 1988; Feliu, 1991; Llopis y García Montero, 2011; Andrés y Lanza, 2014). Pero, aparte de los problemas de carácter documental, el estudio de los salarios de los restantes oficios artesanales se halla dificultado también por la propia complejidad de las condiciones laborales y las modalidades de remuneración. Incluso en el caso de una gran manufactura concentrada, como la fábrica de Guadalajara, se ha destacado que, además de la gran diversidad de las categorías laborales diferenciadas, la principal dificultad para determinar los niveles salariales existentes se deriva del predominio de la remuneración a destajo. Por tanto, el salario percibido dependía directamente del rendimiento y el ritmo del trabajo. Si bien el primero podía derivar, al menos parcialmente, de la habilidad personal o el utillaje utilizado, el segundo estaba condicionado por factores externos, como el clima, los días festivos o las exigencias comerciales (González Enciso, 1980, pp. 433-434). La variación anual del ritmo de la producción se ha destacado también en otros estudios sobre la actividad manufacturera, como es el caso de la pañería segoviana o el artesanado parisino (García Sanz, 1986, pp. 225-226; Sonenscher, 1996, p. 306). Sin embargo, pocas veces se ha vinculado su existencia con la disponibilidad de la materia prima. La incidencia de este factor podía adquirir un carácter crucial en aquellos sectores en los que su obtención tenía un marcado carácter estacional, como es el caso de la industria de la seda. De hecho, en la principal zona productora de seda de la India, la región de Karnataka, se ha destacado que, junto con la calidad del capullo, es el carácter estacional de su obtención el que determina aún hoy en día no solo los precios de la fibra, sino también las ganancias de las unidades dedicadas a su elaboración (Vasumathi, 2000). La intensa estacionalidad que experimentaba el proceso de comercialización de la seda se ha podido comprobar ya en el estudio realizado sobre el mercado de este producto en la ciudad de Valencia a finales del siglo 
XVIII (Franch, 1990). Hacia ella afluía la mayor parte de la materia prima obtenida en el territorio valenciano, que constituía la principal zona productora de seda en la España de la época. En consecuencia, su actividad reflejaba perfectamente el ritmo de producción experimentado en el proceso de elaboración de la materia prima. No obstante, su estacionalidad podía incidir también en las fases posteriores del proceso de producción, como se desprende de las variaciones mensuales del número de telares activos que se han detectado en los registros disponibles en la segunda mitad del siglo XVIII (Franch, 2000, pp. 98-99). Teniendo en cuenta la trascendencia que el sector tenía en la economía valenciana de la época, ya que la seda constituía la producción más valiosa de su agricultura de regadío y su elaboración posterior daba ocupación a la mayor parte de la población existente en la ciudad de Valencia, no cabe duda que el ritmo estacional aludido debió tener un intensa incidencia en la actividad laboral del personal ocupado en su realización. El presente trabajo pretende poner de manifiesto la trascendencia de este fenómeno, aportando, además, información adicional sobre la remuneración obtenida por la mano de obra ocupada en una actividad que se realizaba básicamente a destajo.

\section{El carácter estacional de la hilatura de la seda y las implicaciones labo- rales del cambio del sistema de producción}

El carácter estacional de la actividad era especialmente intenso en el proceso de hilatura de la seda, que se realizaba de forma dispersa en el mundo rural, constituyendo una derivación de la actividad agrícola. Los cosecheros trataban de proceder rápidamente a la enajenación de la seda que obtenían, ya que los ingresos que ello generaba les facilitaban el abono de las rentas que pesaban sobre sus explotaciones. Como la cosecha solía iniciarse a mediados de mayo y el plazo habitual de abono de las rentas estaba fijado en el día de San Juan, se concentraban entonces una gran cantidad de pequeñas operaciones de compraventa, como ha puesto de manifiesto el análisis de los registros del contraste de la seda de la ciudad de Valencia (Franch, 1990). Pero a la acción individual de los pequeños campesinos se añadió en el siglo XVIII el afán especulativo de los intermediarios que trataban de obtener ganancias rápidas adquiriendo el capullo obtenido por aquellos y contratando la realización de su hilatura para proceder inmediatamente a su venta en el contraste. Según destacaba Josep Lapayese, eran estos «compradores por granjería» los que más contribuían a deteriorar la calidad de la fibra de seda valenciana, ya que realizaban todo tipo de abusos y adulteraciones con el fin de incrementar las ganancias que obtenían (Lapayese, 1779, p. 149). Sus presiones incidieron también sobre los hilanderos o hilanderas 
que contrataban para elaborar la fibra de seda, ya que les pagaban a destajo, lo que daba lugar a que estos acelerasen al máximo el ritmo de trabajo con el fin de obtener las mayores ganancias posibles en una actividad que tenía, además, una breve duración temporal. En todo caso, aunque la contratación de la mano de obra se realizara estipulando un jornal diario, se esperaba con ello la obtención de una productividad mínima que requería la realización de la operación con una excesiva rapidez. Esto es lo que explica las frecuentes denuncias de que esta se efectuaba con un número excesivo de agujas, ya que, frente a las dos que debían tener los tornos según las ordenanzas de Granada de 1600, en el siglo XVIII las hilanderas llegaban a trabajar con cinco agujas, y los hilanderos con entre cinco y siete de ellas (Lapayese, 1779, p. 168; y 1794, p. 19 y 21). La precipitación con la que procedían daba lugar a que no se efectuase una correcta selección de los capullos, con lo que se obtenía un hilo muy irregular, al que se le añadía, además, aceite para facilitar el proceso e incrementar su peso. Como el ojal de las agujas era muy grande, dejaba pasar también todo tipo de impurezas y generaba una fibra muy imperfecta que solía tener una forma más bien chata o aplastada, en lugar de redonda. Estas deficiencias podían pasar relativamente desapercibidas en los tejidos tradicionales, ya que el criterio de calidad que se utilizaba se basaba en el peso y la consistencia del género elaborado, apreciándose sobre todo su riqueza y durabilidad. Sin embargo, estas características eran cada vez menos apreciadas en el siglo XVIII, ya que la irrupción de la moda propició la elaboración de tejidos cada vez más ligeros y vistosos, otorgándose una mayor importancia al modelo de tejido elaborado y a la perfección de su diseño (Poni, 1993; Pérez, 2008). En estas circunstancias, resultaba mucho más evidente cualquier deficiencia de la fibra utilizada, por lo que era crucial disponer de un hilo uniforme, limpio, redondo y cada vez más delgado y resistente (Lapayese, 1794, p. 19).

En las zonas productoras de seda más avanzadas de la Europa de la época se produjo una rápida adaptación a las nuevas exigencias del mercado mediante la mejora del utillaje utilizado y la concentración de la actividad en establecimientos fabriles (Poni, 1976). Pero, más que los métodos utilizados en el norte de Italia, fueron los perfeccionados por Jacques de Vaucanson en Francia los que se trataron de difundir en España a partir de la década de 1760 . Su principal manifestación fue el privilegio que se otorgó en 1769 al técnico de origen francés Guillermo Reboull con el fin de crear una fábrica en la localidad valenciana de Vinalesa en la que se procediese a su aplicación (Martínez Santos, 1981, pp. 188-189). La empresa acabó siendo llevada a cabo por el comerciante francés José Lapayese, quien se convirtió en el principal difusor de los nuevos métodos, tanto para la hilatura como el torcido de la seda, realizando incluso pequeñas mejoras de los tornos construidos por Reboull. Cabría destacar, entre ellas, la creación de un torno doble, que permitía trabajar con 
la misma caldera en la que se ahogaba el capullo a dos hilanderas, reduciendo consiguientemente a la mitad el consumo de energía que se realizaba. Su actividad fue intensamente apoyada por las principales instituciones valencianas, que adoptaron numerosas iniciativas para facilitar la difusión del nuevo método de hilatura entre los cosecheros, proporcionándoles gratuitamente los nuevos tornos y otorgándoles bonificaciones por cada libra de seda que acreditasen haber elaborado con el nuevo sistema. Sin embargo, el esfuerzo realizado no logró los resultados que cabría esperar, ya que los cosecheros acabaron devolviendo los tornos entregados, llegando la Junta de Comercio de Valencia a reconocer amargamente en 1796 que nadie los utilizaba ya en ese momento. Tampoco tuvieron éxito las tentativas realizadas para la creación de establecimientos fabriles similares al de Vinalesa. Incluso esta fábrica se vio obligada a cerrar como consecuencia de la suspensión de pagos que presentó en 1794 su principal socio capitalista, Juan Bautista Condou, realizándose algunas tentativas para lograr su reapertura entre 1805 y 1808 y en las décadas de 1820 y 1830 , y procediéndose finalmente a su desmantelamiento en 1841 (Franch, 2004).

Tras comprobar la intensa resistencia suscitada por las campañas de difusión de los nuevos métodos de hilatura, a partir de mediados de la década de 1780 las instituciones valencianas se resignaron a perseguir solamente la mejora del sistema tradicional. Como indicaba la Sociedad Económica de Amigos del País de Valencia en el informe que emitió al respecto en 1788, las fábricas valencianas solo necesitaban que el $10 \%$ de la seda que consumían fuese muy fina y delgada, por lo que la mayor parte de la cosecha podía seguir siendo elaborada en los tornos tradicionales (VV.AA., 1794, p. 7). Bastaba simplemente con corregir los abusos que se realizaban en el proceso, eliminando el aceite y otros aditivos que se utilizaban en ello; reduciendo el número de agujas con las que se trabajaba, que debían ser un máximo de cinco para los hilanderos y de cuatro para las hilanderas; y prohibiendo el trabajo a destajo. Realmente, todo parece indicar que la rapidez con la que se pretendía realizar el trabajo era una de las causas fundamentales que determinaban la mala calidad de la fibra que se obtenía. En la disertación que realizó el presbítero Francisco Ortells comparando el sistema tradicional de hilatura con el nuevo método de Vaucanson, destacó como una de las cuatro «preocupaciones» que dificultaban la difusión de éste el hecho de que «... la hilaza por medio de mugeres es más costosa al labrador cosechero, y casi imposible su establecimiento...» (Ortells, 1783, pp. 134-146). La razón básica de ello era la mayor lentitud del trabajo que estas realizaban, llegando a calcular que los hombres podían triplicar en exceso su productividad. Ciertamente, trabajando con tornos que disponían de un mayor número de agujas y de una rueda en la que se enrollaban las madejas de mayores dimensiones, los hombres podían hilar diariamente hasta 14 o 15 libras de seda, mientras que las mujeres solo lograban 
obtener un máximo de 6 o 7 libras. Ahora bien, los niveles más elevados de productividad solo se lograban cuando se hilaba la seda más gruesa e imperfecta, que se utilizaba para la trama de las telas. Si se pretendía obtener la fibra más fina y delicada que se empleaba en la urdimbre, la seda pelo, el ritmo de trabajo debía ser inferior, y todo parece indicar que las mujeres lograban realizarlo con mayor perfección. Así, la seda pelo hilandera era la más cotizada en el mercado, pagándose a un precio superior a la hilandero y, por supuesto, la trama y otras modalidades inferiores. Pero, además, el análisis de los registros del contraste ha puesto de manifiesto que era también la más demandada por los fabricantes. En el año 1796, por ejemplo, aquella representó el $34,2 \%$ de la seda comercializada, frente al 7,2\% que supuso la modalidad hilandero y el 20,3\% que representó la trama ${ }^{2}$. Por tanto, a pesar de las afirmaciones de Ortells, todo parece indicar que la hilatura había experimentado ya un intenso proceso de feminización antes de la implantación del sistema fabril, concentrándose su actividad en la elaboración de la fibra de mayor calidad.

Realmente, la hilatura era un trabajo muy duro que tenía un intenso carácter estacional y que requería el desplazamiento de los trabajadores a la localidad en la que residían los cosecheros que les contrataban, lo que explica la complejidad y elevada entidad de la remuneración que percibían. El trabajo se realizaba en jornadas agotadoras de 12 a 14 horas en unas condiciones penosas, ya que, además del intenso ritmo con que se realizaba, se debía soportar el calor del pequeño horno en el que se procedía al ahogado de los capullos de seda. De ahí que, según destacaba Lapayese, «... con dificultad pueden aguantar un mes, en particular la hilandera, cuya salud se quebranta y su ropa se pone como su rostro en el más deplorable estado...». Pero, en contrapartida, se percibía un salario mucho más elevado que el que obtenían regularmente los jornaleros habituales. El mismo Lapayese lo planteaba crudamente en los siguientes términos:

«... y qualquiera puede conocer que es más abuso que necesidad el pagar un jornal de seis reales, manteniendo además de esto a la hilandera, y dos reales y ocho maravedís a la muchacha menadora, pues no se ve otra cosa sino jornaleros que no ganan más que los mismos quatro reales, con los quales se mantienen con la muger y los hijos...» (Lapayese, 1779, pp. 158-159).

Del resto de modalidades, cabe destacar las que procedían del extranjero, que llegaron a representar el 28,5\% del total (Franch, 1990, p. 279). Sobre la evolución de los precios de las diversas modalidades de seda a finales del siglo XVIII, ver Palop, 1977, p. 270. 
Tabla 1. Comparación de la información proporcionada por José Lapayese y Francisco Ortells sobre el coste de la hilatura de seda con los tornos tradicionales y el torno doble mediante el sistema Vaucanson

Seda hilandera elaborada con el torno tradicional

\begin{tabular}{|c|c|c|c|c|c|c|}
\hline & \multicolumn{3}{|c|}{ Josep Lapayese } & \multicolumn{3}{|c|}{ Francisco Ortells } \\
\hline & $\begin{array}{c}\text { Libras } \\
\text { peso }\end{array}$ & $\begin{array}{l}\text { Reales } \\
\text { vellón }\end{array}$ & $\begin{array}{c}\% \text { coste } \\
\text { total }\end{array}$ & $\begin{array}{c}\text { Libras } \\
\text { peso }\end{array}$ & $\begin{array}{l}\text { Reales } \\
\text { vellón }\end{array}$ & $\begin{array}{c}\% \text { coste } \\
\text { total }\end{array}$ \\
\hline Capullo de seda & 36 & 160,9 & 88,5 & 45 & 237,2 & 91,9 \\
\hline Mano de obra & & 16,5 & 9,1 & & 16,5 & 6,4 \\
\hline Carbón & & 4,5 & 2,4 & & 4,5 & 1,7 \\
\hline Coste total & & 181,9 & 100 & & 258,2 & 100 \\
\hline Seda obtenida & 4 & & & 5 & & \\
\hline Coste por libra & & 45,5 & & & 51,6 & \\
\hline Coste m. obra por libra & & 4,1 & & & 3,3 & \\
\hline
\end{tabular}

Seda hilandera elaborada con el torno doble mediante el sistema de Vaucanson

\begin{tabular}{|c|c|c|c|c|c|c|}
\hline & \multicolumn{3}{|c|}{ Josep Lapayese } & \multicolumn{3}{|c|}{ Francisco Ortells } \\
\hline & $\begin{array}{c}\text { Libras } \\
\text { peso }\end{array}$ & $\begin{array}{l}\text { Reales } \\
\text { vellón }\end{array}$ & $\begin{array}{c}\% \text { coste } \\
\text { total }\end{array}$ & $\begin{array}{c}\text { Libras } \\
\text { peso }\end{array}$ & $\begin{array}{l}\text { Reales } \\
\text { vellón }\end{array}$ & $\begin{array}{c}\% \text { coste } \\
\text { total }\end{array}$ \\
\hline Capullo de seda & 50 & 223,5 & 93,1 & 45 & 237,2 & 93,5 \\
\hline Mano de obra & & 12 & 5 & & 12 & 4,7 \\
\hline Carbón & & 4,5 & 1,9 & & 4,5 & 1,8 \\
\hline Coste total & & 240 & 100 & & 253,7 & 100 \\
\hline Seda obtenida & 5 & & & 5 & & \\
\hline Coste por libra & & 48 & & & 50,7 & \\
\hline Coste m. obra por libra & & 2,4 & & & 2,4 & \\
\hline
\end{tabular}

Tanto Lapayese como Ortells proporcionan suficiente información para conocer las diversas modalidades de remuneración del trabajo en la hilatura tradicional y valorar el cambio de las condiciones laborales que implicó la introducción de los nuevos tornos y su concentración en un establecimiento fabril. Las referencias salariales que aportan son prácticamente coincidentes, variando solamente su incidencia sobre los costes totales de producción debido a la diversa productividad que atribuyen a los tornos y las hilanderas en ambos sistemas. En el caso de la hilatura tradicional, ambos coinciden en que la hilandera percibía un jornal diario de 6 reales de vellón y la 
«menadora» que le auxiliaba cobraba 2 reales y 8 maravedís. Pero, además, estimaban que su manutención podía ascender a una cantidad equivalente, por lo que el coste total de un día de trabajo ascendía a 16,5 reales de vellón (véase tabla 1). No obstante, Lapayese estimó su productividad en 4 libras de seda, lo que requería la utilización de 36 libras de capullo, cuyo coste situó en 160,9 reales. Añadiendo 4,5 reales por el precio del carbón que se consumiría, obtuvo un coste total de 181,9 reales, lo que implicaba que cada libra de seda obtenida saldría a 45,5 reales (Lapayese, 1779, pp. 152-155). En cambio, Ortells elevó la productividad diaria a 5 libras de seda, lo que requería la utilización de 45 libras de capullo, cuyo valor estimó en 237,2 reales de vellón. De ahí que el coste de producción de cada una de aquellas se elevase hasta los 51,6 reales de vellón (Ortells, 1783, pp. 66-74 y 123-129)3. A pesar de estas diferencias, lo que cabe destacar es la escasa incidencia que suponía la mano de obra sobre los costes totales, situándose entre el 6,4\% y el 9,1\%.

Con respecto a los hilanderos, Lapayese se limitó a indicar globalmente que su productividad diaria era de entre 8 y 10 libras de seda, llegando algunos a ganar un jornal diario de 22,5 reales de vellón, además de la manutención (Lapayese, 1779, p. 168). Sin embargo, Ortells proporcionó una información mucho más detallada y rica en matices (véase tabla 2). La productividad de 10 libras diarias solo se alcanzaba cuando elaboraban seda trama a destajo. En este caso podían ajustarse a 4 sueldos por libra producida sin incluir la comida, lo que les permitía ganar unos 30,1 reales de vellón diarios. Pero si se incluía la comida el ajuste solía ser a 3 sueldos por libra producida, con lo que obtenían los 22,5 reales de vellón que indicaba Lapayese. Como el valor de la comida se estimaba en unos 10 reales de vellón diarios, el coste total se elevaba, en este caso, a 32,5 reales de vellón. Ahora bien, cuando se trabajaba a jornal se puede comprobar que el hilandero estaba auxiliado por un ayudante y contaba, además, con el apoyo de otra persona para atender el fuego del horno en el que se ahogaba el capullo. Los dos primeros percibían una remuneración diaria de unos 15 reales de vellón, mientras que el último solo percibía 1,5 reales. Aunque no se precisaba, todo parece indicar que el hilandero ganaría en torno a los 11 reales de vellón, mientras que su ayudante obtendría los 4 reales restantes. En todo caso, a estos salarios cabía añadir la comida, que se estimaba en los 10 reales diarios indicados anteriormente. Al trabajar a jornal, la productividad diaria era mucho más baja, obteniéndose unas 8 libras de seda trama o 6 libras en el caso de que se elaborase seda pelo. En función de ello, los costes de producción oscilaban entre los 51 y los 52,5

La información de Ortells se ofrece en moneda valenciana, por lo que se ha transformado en castellana con la siguiente equivalencia: 1 libra $=15$ reales y 2 maravedís de vellón. Hay que tener en cuenta que la libra valenciana tenía 20 sueldos, y el sueldo 12 dineros. 
reales de vellón por libra, y la mano de obra representaba entre el 6 y el 8,5\% de ellos (Ortells, 1783, pp. 66-77).

Tabla 2. Coste de la hilatura de seda por parte de los hilanderos en los tornos tradicionales, según la información proporcionada por Francisco Ortells, en función de las diversas calidades elaboradas y modalidades de contratación

\begin{tabular}{|l|c|c|c|}
\hline & \multicolumn{3}{|c|}{ Seda hilandera pelo } \\
\hline & Libras peso & Reales vellón & \% coste total \\
\hline Capullo de seda & 54 & 284,6 & 90,2 \\
\hline Mano de obra & & 26,5 & 8,4 \\
\hline Carbon & & 4,5 & 1,4 \\
\hline Coste total & & $\mathbf{3 1 5 , 6}$ & $\mathbf{1 0 0}$ \\
\hline Seda obtenida & 6 & & \\
\hline Coste por libra & & 52,6 & \\
\hline Coste m. obra por libra & & 4,4 & \\
\hline
\end{tabular}

\begin{tabular}{|l|c|c|c|}
\hline & \multicolumn{3}{|c|}{ Seda hilandera trama } \\
\hline & Libras peso & Reales vellón & \% coste total \\
\hline Capullo de seda & 72 & 379,5 & 92,4 \\
\hline Mano de obra & & 26,5 & 6,5 \\
\hline Carbón & & 4,5 & 1,1 \\
\hline Coste total & & $\mathbf{4 1 0 , 5}$ & $\mathbf{1 0 0 , 0}$ \\
\hline Seda obtenida & 8 & & \\
\hline Coste por libra & & 51,3 & \\
\hline Coste m. obra por libra & & 3,3 & \\
\hline
\end{tabular}

\begin{tabular}{|l|c|c|c|}
\hline & \multicolumn{3}{|c|}{ Seda hilandera trama a destajo con comida } \\
\hline & Libras peso & Reales vellón & \% coste total \\
\hline Capullo de seda & 90 & 474,3 & 92,7 \\
\hline Mano de obra & & 32,6 & 6,4 \\
\hline Carbón & & 4,5 & 0,9 \\
\hline Coste total & & $\mathbf{5 1 1 , 4}$ & $\mathbf{1 0 0 , 0}$ \\
\hline Seda obtenida & 10 & & \\
\hline Coste por libra & & 51,1 & \\
\hline Coste m. obra por libra & & 3,2 & \\
\hline
\end{tabular}




\begin{tabular}{|l|c|c|c|}
\hline & \multicolumn{3}{|c|}{ Seda hilandera trama a destajo sin comida } \\
\hline & Libras peso & Reales vellón & \% coste total \\
\hline Capullo de seda & 90 & 474,4 & 93,2 \\
\hline Mano de obra & & 30,1 & 5,9 \\
\hline Carbón & & 4,5 & 0,9 \\
\hline Coste total & & $\mathbf{5 0 8 , 0}$ & $\mathbf{1 0 0 , 0}$ \\
\hline Seda obtenida & 10 & & \\
\hline Coste por libra & & 50,9 & \\
\hline Coste m. obra por libra & & 3,0 & \\
\hline
\end{tabular}

A partir de estos datos se puede deducir que el salario femenino era alrededor de un $45 \%$ inferior al masculino de la misma categoría, sin tener en cuenta el coste de la comida, que era bastante similar en ambos casos. Pero su incidencia sobre los costes totales de la producción dependía de la productividad obtenida. Según los datos de Ortells, el coste por libra de la remuneración del trabajo de las hilanderas era de 3,3 reales de vellón. En el caso de los hilanderos, se elevaba hasta 4,4 reales cuando elaboraban la seda pelo de mayor calidad. Esta circunstancia es la que puede explicar la escasa entidad que representaba este tipo de seda en los registros del contraste analizados. En cambio, cuando los hilanderos elaboraban seda trama, el coste por libra de su remuneración se aproximaba mucho al de las hilanderas, situándose en 3,3 reales. Pero la modalidad de contratación más ventajosa para los cosecheros era cuando los hilanderos se ajustaban a trabajar a destajo alimentándose por su cuenta, ya que entonces el coste por libra se reducía a unos 3 reales de vellón. Esto es lo que explica que se siguiese practicando a pesar de estar reiteradamente prohibida. En cualquier caso, la repercusión de la mano de obra sobre los costes totales de producción era algo más baja en el caso del trabajo masculino debido a su mayor productividad.

A pesar de la escasa repercusión que tenían los salarios en los costes de producción, la introducción del nuevo método de hilatura mediante el sistema Vaucanson supuso una drástica reducción de la remuneración obtenida por la mano de obra. La causa fundamental que lo permitió fue la eliminación de la concentración estacional del trabajo. Con tal finalidad, Lapayese aconsejaba que se procediese al ahogado del capullo como una fase previa e independiente de la hilatura, lo que permitía efectuar esta operación con tranquilidad a lo largo del resto del año. Incluso indicaba un método de ahogado al horno que permitía conservar los capullos de seda dos años sin que mermase su calidad. De esta forma, se podía contratar a las hilanderas en cualquier momento ofreciendo el salario que se abonaba habitualmente a los jornaleros, es decir, a 4 reales de vellón, mientras que a las «menadoras» se les podía pagar la mitad 
de este jornal, 2 reales, sin proporcionarles, además, en ambos casos la manutención, que debía correr de su cargo. Como el torno que había construido era doble, en cada uno de ellos trabajaban dos hilanderas y dos «menadoras», por lo que el salario total que les abonaba eran los 12 reales de vellón que figuran en la tabla 1. Teniendo en cuenta que en el sistema tradicional cada equipo de ambas categorías tenía un coste total de 16,47 reales de vellón y que en el nuevo método se había bajado a 6 reales, la reducción experimentada era del 63,6\%. Por tanto, el cambio del sistema de producción que implicaba la adopción de los nuevos tornos y su concentración en establecimientos fabriles suponía una drástica caída de la remuneración del trabajo. No obstante, este retroceso podría estar compensado parcialmente por la mayor duración y regularidad de la contratación de la mano de obra, que podía mantenerse teóricamente a lo largo de todo el año. Esto es lo que hizo Lapayese en su fábrica de Vinalesa, en la que instaló 30 tornos dobles en los que estaban ocupadas 120 mujeres. Pero, aunque podían elaborar 40.000 libras de seda trabajando todo el año, consideraba conveniente concluir el proceso antes de que llegase la época de la lluvia, ya que la excesiva humedad reducía la calidad de la seda obtenida. Por ello, reducía la fase de producción a cuatro meses, en los que calculaba que se podían producir unas 18.000 libras de seda (Lapayese, 1779, p. 206) ${ }^{4}$. La mano de obra contratada era exclusivamente femenina, lo que justificaba tanto por la resistencia que ofrecerían los hombres a trabajar por un salario tan inferior al que estaban acostumbrados como, sobre todo, por la mayor calidad de la seda que aquellas elaboraban. Por tanto, el nuevo sistema de producción culminó el proceso de feminización de la hilatura que había comenzado a experimentarse ya con el método tradicional ${ }^{5}$.

$4 \quad$ En las páginas 122-123 defiende los beneficios del método de ahogado del capullo al horno. Con respecto al salario habitual de los jornaleros, hay que tener en cuenta que el jornal de los peones de la construcción se mantuvo en 6 sueldos (unos 4,5 reales de vellón) hasta principios de la década de 1780, cuando inició una escalada que lo elevó hasta 8 sueldos (unos 6 reales de vellón) en los primeros años del siglo XIX (Palop, 1977, pp. 275-276). En el periodo 1780-1799, la media fue de 6,6 sueldos, lo que representaba unos 5 reales de vellón y equivalía a unos 6 gramos de plata. Su salario era, por tanto, inferior al percibido por la misma categoría laboral en Madrid (6,1 gramos de plata), Barcelona (7,6 gramos de plata) y las ciudades europeas más dinámicas, como Amberes, Amsterdam o Londres (Llopis y García, 2011, p. 306). De todas formas, en la relación del personal ocupado en las obras de construcción del puerto de Valencia en 1797 se puede apreciar que los peones eran el núcleo principal de la mano de obra existente, ya que los 202 contratados representaban el $45 \%$ del total. De ellos, solo 18 percibían una remuneración de 5 reales de vellón, 163 de 4,5 reales y 21 de 4 reales (Franch, 2007, pp. 192-194). Por tanto, el jornal de 4 reales de vellón que abonaba Lapayese era el que percibían los peones de categoría inferior, ya que, como se verá posteriormente, se mantuvo en la fábrica de Vinalesa a principios del siglo XIX. Los 4 reales de vellón equivalían a unos 4,8 gramos de plata, lo que suponía un nivel de remuneración inferior al de los jornaleros y peones menos cualificados de Barcelona o Castilla la Nueva, cuyos salarios superaban los 5 gramos de plata desde mediados de la década de 1770 (Feliu, 1991, II, p. 126).

5 Aunque Carmen Sarasúa ha sostenido que una de las principales ventajas del nuevo método de hilatura era la apertura de la manufactura de la seda a la mano de obra femenina y ha insertado el apoyo 
Pero el mayor inconveniente del nuevo sistema era su inferior productividad. Como se ha indicado, las cuatro mujeres que trabajaban en los nuevos tornos dobles podían elaborar diariamente la misma cantidad de seda que obtenían dos de ellas en los tornos tradicionales. La razón básica era que las hilanderas operaban en ellos con dos agujas, en lugar de las cuatro o cinco que atendían en los tornos tradicionales. Pero, además, Lapayese consideró también que en los nuevos tornos el rendimiento del capullo de seda era inferior, necesitando 10 libras de este para obtener una libra de seda, frente a las 9 libras que se requerían en los tornos tradicionales. Por el contrario, Ortells aportó en su disertación numerosos testimonios de cosecheros que habían obtenido en los nuevos tornos el mismo rendimiento del capullo de seda que en los antiguos, y atribuyó el cálculo de Lapayese a la prudencia propia de los comerciantes (Ortells, 1783, p. 106). Esta misma circunstancia le había inducido a este a considerar que en los tornos tradicionales las hilanderas solían elaborar cuatro libras de seda diarias, mientras que Ortells elevó su productividad a las cinco que lograban con frecuencia. Estas diferencias son las que explican los distintos resultados obtenidos por ambos en la comparación que realizaron sobre los costes de producción de ambos sistemas que se ha plasmado en la tabla 1. Al atribuir una productividad menor a las hilanderas en el sistema tradicional, Lapayese redujo el valor de la seda transformada y, consiguientemente, los costes totales de producción. En cambio, el menor rendimiento de los capullos de seda en el nuevo sistema requería una mayor cantidad de materia prima para obtener la misma producción de fibra que en el sistema tradicional, lo que elevaba los costes totales de producción. Todo ello es lo que explica que, según los cálculos de Lapayese, la obtención de una libra de seda en los nuevos tornos tuviese un coste superior en 2,5 reales al que se lograba con los tornos tradicionales. Por el contrario, corrigiendo estos dos factores en la forma indicada anteriormente, Ortells invirtió la relación y consideró que con los nuevos tornos el coste era inferior en 0,9 reales al que se alcanzaba con el sistema tradicional. Pero, al margen de estas discrepancias, en los cálculos de ambos se aprecia claramente que el

estatal a su difusión en el marco de una política económica que pretendía modificar la división del trabajo tradicional para favorecer la incorporación de la mujer a las actividades manufactureras, hay que tener en cuenta que ésta ya había sido muy intensa con los métodos tradicionales de hilatura, como se ha podido comprobar en el presente estudio. Lo que si resulta evidente es que las nuevas manufacturas que se crearon para la introducción de los nuevos métodos de hilatura de la seda recurrieron básicamente a la contratación de la mano de obra femenina para la realización de dicha actividad. Pero en la reducción de los costes de producción que lograron con ello fue, tanto o más importante que este proceso de feminización del trabajo, la eliminación de la variación estacional de la actividad y la concentración de la mano de obra en establecimientos fabriles en los que podía ser sometida a un estricta disciplina laboral, lo que posibilitaba la introducción de innovaciones técnicas que incrementasen su productividad. La tesis anteriormente aludida puede verse en Sarasúa, 2008, pp. 23-39; y en Solà, 2010, p. 115. 
nuevo sistema comportó una intensa reducción del coste de la mano de obra. Según los datos de Ortells, la remuneración abonada por la elaboración de una libra de seda habría descendido un 27\%, mientras que teniendo en cuenta las cifras de Lapayese el retroceso alcanzaría el 41,7\%. Así mismo, la repercusión que suponía sobre los costes totales de producción habría bajado un mínimo de 1,4 puntos, desde el 6,4\% que representaba en el sistema tradicional según Ortells hasta el 5\% que suponía en el nuevo sistema según Lapayese, pudiendo alcanzar los 4,3\% puntos si se adoptasen los cálculos más contrapuestos.

Esta reducción de la remuneración provocó un intenso rechazo al nuevo sistema por parte de los trabajadores del sector, y más teniendo en cuenta que la mano de obra masculina era completamente marginada en su contratación. Por su parte, la menor productividad de la mano de obra y de la materia prima utilizada, junto con los posibles costes superiores del proceso y del nuevo torno que se debía adquirir para su realización, dieron lugar a que los cosecheros tampoco considerasen positivamente su adopción. Evidentemente, la fibra de seda obtenida era de mucha mayor calidad, por lo que, como insistían los defensores del nuevo sistema, se cotizaba a un precio superior en el mercado. Sin embargo, esta ventaja fue también atenuada por la moderación que sufrieron los precios de la seda como consecuencia de la prohibición existente en su exportación y de las importaciones de materia prima extranjera que comenzaron a realizarse a partir de 1785, así como del hundimiento de la cotización de aquella que se producía como consecuencia de las frecuentes crisis bélicas de finales de la centuria (Franch, 2000, pp. 92-97). La escasa rentabilidad del negocio desestimuló también la creación de hilaturas en establecimientos fabriles, que era el sistema mediante el cual se podían obtener las mayores ventajas que proporcionaba el nuevo método de hilatura. Las vicisitudes que experimentó la fábrica de Vinalesa reflejan perfectamente los excesivos riesgos que tenía el negocio en dicho contexto, y más teniendo en cuenta que su construcción requirió la inversión de unos dos millones de reales de vellón. Pero la tentativa de revitalización de la empresa que emprendió en 1805 Pedro Vicente Galabert pone de manifiesto que era este sistema el que permitía continuar reduciendo los costes de producción mediante la introducción de pequeñas mejoras técnicas. Las cuentas que presentó al respecto el 5 de marzo de 1806 revelan que los salarios que se abonaban a las 120 mujeres que trabajaban en los 30 tornos dobles de hilar que existían en la fábrica seguían siendo los mismos que los que indicaron Lapayese y Ortells en las décadas de 1770 y 1780: las hilanderas percibían 4 reales de vellón y las «menadoras» 2 , por lo que el coste de la mano de obra de cada torno era de 12 reales diarios. Galabert precisa, no obstante, que la jornada laboral era de 12 horas, y que los días de trabajo anuales eran 240. Estas condiciones eran algo mejores a las que indicaba Tomás Pérez Estala en el dictamen que realizó 
en 1803 para las actividades similares realizadas por las desmotadoras e hilanderas de lana en las fábricas segovianas, ya que las primeras ganaban entre 3 y 3,5 reales y las segundas entre 2 y 2,5 reales, siendo las jornadas de 13 horas diarias (de las 8 de la mañana a las 9 de la noche) y 280 los días laborales que computaba en cada año (Franch, 1991, p. 128) ${ }^{6}$. Por su parte, la productividad diaria que atribuía Galabert a cada torno era algo inferior a la que indicaban Lapayese y Ortells, al fijarla en 4,5 libras de seda. Quizás lo que pretendía con ello era intensificar el incremento de la productividad que había logrado obtener con la mejora que realizó a los tornos. Esta consistió en la sustitución de las ruedas de madera que se usaban para accionar la devanadera en la que se plegaban las madejas de la seda por otras de hierro y bronce que se habían capturado a los ingleses en 1781 y no se habían utilizado desde entonces. Con ello logró incrementar la rapidez y precisión de los tornos, elevando su productividad en un 55,5\%, según constató una comisión de la Sociedad Económica de Amigos del País que los inspeccionó. Así, en lugar de las 4,5 libras que se hilaban diariamente en cada uno de ellos, se podían obtener 7 libras, lo que implicaba una reducción del coste de producción de 1,7 reales de vellón por libra. Considerando que la fábrica podía producir anualmente unas 50.400 libras de seda, la simple mejora realizada permitía obtener un ahorro total de 83.990,1 reales de vellón. Evidentemente, esta última estimación era muy optimista, ya que la fábrica nunca trabajó a pleno rendimiento. Pero ponía claramente de manifiesto que, una vez reducidos los salarios al límite imprescindible para permitir la supervivencia de la mano de obra, solo se podía incrementar su rentabilidad mediante la introducción de innovaciones técnicas que acelerasen el ritmo de la producción.

\section{La conflictividad existente en la remuneración del trabajo en el devanado y el torcido de la seda}

Realmente, más que en la hilatura, los mayores avances en el proceso de mecanización que implicaba la introducción de las innovaciones realizadas por Jacques Vaucanson afectaban a las operaciones del devanado y torcido de la seda. En el sistema tradicional, ambas tenían un carácter básicamente urbano y eran controladas por el colegio de torcedores, ya que, aunque la corporación regulaba propiamente la segunda actividad, sus miembros eran los que contrataban la realización de la primera a

En la Real Fábrica de Paños de Guadalajara, los días de trabajo anuales eran 270 (González Enciso, 1980 , p. 433). Las cuentas presentadas por Galabert sobre la fábrica de Vinalesa en 1806 se hallan en Archivo General de Simancas (en adelante A.G.S.), Consejo Supremo de Hacienda, leg. 385, exp. $n^{\circ} 2$. 
la abundante mano de obra femenina que existía en la ciudad y que estaba dispuesta a obtener unos pequeños ingresos trabajando a destajo en sus domicilios. Realmente, la práctica más habitual era que los fabricantes comprasen la seda hilada en madejas y la entregasen a los torcedores para que procediesen a su devanado y torcido, abonándoles una remuneración acordada por cada libra de seda que devolviesen en estas condiciones. No obstante, eran muchas veces también los propios torcedores u otros intermediarios los que efectuaban dicho negocio con el fin de maximizar sus ingresos y obtener unos beneficios de carácter especulativo, vendiendo luego la seda torcida a los fabricantes. En todo caso, el papel crucial que jugaban los torcedores en este sistema les convirtió en el blanco fundamental de las críticas que se realizaron a sus prácticas abusivas y monopolísticas, lo que, junto con su firme oposición a la introducción de los nuevos métodos procedentes de los países europeos más avanzados, acabaría conduciendo a la abolición de la corporación gremial en 1793.

Las madejas de seda obtenidas tras la hilatura debían ser devanadas en carretes para su posterior utilización por parte de los torcedores. Se trataba de una actividad muy laboriosa que requería la intervención de una abundante cantidad de mano de obra, ya que, según destacaba Lapayese, el abastecimiento de un torno necesitaba el trabajo de 70 a 80 mujeres, cantidad que podía llegar a doblarse si la fibra de seda que se devanaba era de mala calidad. De ahí que su realización estuviese muy generalizada entre la población femenina de la ciudad de Valencia, hasta el punto de que aquel indicaba que eran raras las familias o comunidades religiosas que no lo efectuasen con el fin de obtener unos pequeños ingresos adicionales. Esta circunstancia determinaba que el trabajo se realizase a tiempo parcial en el propio domicilio y se remunerase a destajo. El cambio de este sistema de producción resultaba prácticamente imposible con los métodos tradicionales, ya que, como afirmaba Lapayese, «... para pagarlas a jornal sería preciso que los maestros las tuviesen todas a la vista, lo que es dificil o imposible, no teniendo sus casas proporcionadas para contener setenta $u$ ochenta mugeres que necesitan para llevar corriente su torno...» (Lapayese, 1794, pp. 16-17). Pero el deterioro que había experimentado la hilatura de la seda estaba repercutiendo negativamente sobre la actividad de las «rodeteras», como eran conocidas, ya que la mala calidad de la fibra elaborada y las sustancias que se le habían añadido dificultaban considerablemente su trabajo y reducían los ingresos que obtenían. De ahí que los problemas que afectaban a esta actividad comenzasen a estrangular el propio desarrollo de la sedería, lo que planteó claramente Lapayese al afirmar: «... estas fábricas carecen muy a menudo de seda torcida, no por falta de tornos, sino por falta de seda devanada en los rodetes...» (Lapayese, 1779, p. 31). Ciertamente, tal vez lo que pretendía con ello era subrayar la trascendencia de la máquina que había creado para acelerar el ritmo de producción. Consistía en un mecanismo 
que accionaba al mismo tiempo 70 rodetes y que podía ser atendido por dos mujeres, con lo que la productividad de cada una de ellas se había multiplicado por 35. Podía ser accionado fácilmente con una manija por un muchacho e, incluso, un inválido, y ocupaba el espacio de tres devanaderas tradicionales. Pero en la fábrica de Vinalesa construyó 19 máquinas de este tipo para devanar y 3 para doblar la seda, que situó en la estancia superior de las 22 máquinas de torcer, siendo todas ellas accionadas por la fuerza de tracción hidráulica que proporcionaba la acequia de Moncada. Según la descripción que realizó Cavanilles posteriormente, cada una de las 19 primeras «...pone en movimiento 36 madexas, que cuida con comodidad una sola muchacha...», mientras que en las tres restantes trabajaban 6 mujeres «...cuidando de treinta rodetes cada una, quando en las máquinas ordinarias, llamadas vulgarmente rodines, una muger no puede cuidar más que de un solo rodete...» (Cavanilles, 1958, I, p. 148). No cabe duda, pues, que la mecanización de la operación había incrementado considerablemente la productividad de la mano de obra.

La remuneración obtenida por las mujeres que trabajaban en el devanado tradicional es muy difícil de calcular, ya que, como se ha indicado, la actividad tenía un carácter doméstico y complementario al resto de las labores cotidianas, y solía realizarse a destajo. No obstante, el análisis de la documentación generada por la Compañía de Nuestra Señora de los Desamparados nos permite disponer de bastante información sobre la materia. A finales de 1779 esta recibió una oferta por parte de la Casa de la Misericordia, que podía proporcionar el trabajo de unas 50 mujeres dispuestas a realizar la actividad. Con tal finalidad, se designó a un responsable de su supervisión y se contrataron a tres maestras para que dirigiesen y controlasen la labor de aquellas. Su remuneración no se ha logrado conocer, por el momento, constando solamente que las rodeteras percibían un jornal de 2 reales de vellón diarios. Tal vez estos eran los ingresos más habituales de la mano de obra femenina que realizaba este tipo de actividad, ya que en la «escuela patriótica» que se creó en esta época en la localidad de Albal para el aprendizaje de la hilatura de lienzo se indicaba que «...las instruidas, vendiendo sus hilazas, ganaban sin mucho trabajo ni faltar a sus haciendas domésticas, más de dos reales de vellón...» (VV.AA., 1777, p. 59). En todo caso, los problemas que generaba la gestión y el control de la mano de obra dio lugar a que la compañía acordase el 18 de agosto de 1780 la realización de una contrata para la ejecución a destajo de dicha operación, abonando a su responsable 5 sueldos por libra de seda devanada. La paralización de las fábricas como consecuencia de la guerra permitió reducir incluso el precio al año siguiente hasta 4,5 sueldos por libra en el caso de la seda hilandera, y 4 sueldos para la modalidad hilandero. Pero, aun así, la compañía consideraba «enfadoso» el control del enrodetado, ya que se generaban muchos fraudes y se incrementaba el peso de la seda devanada al añadir 
el peso de la madera de los rodetes vacíos, por lo que el 9 de enero de 1782 se acordó incluir esta operación en la contrata que se había realizado con el responsable de los tornos de que disponía, entregándole la seda en rama para que la devolviese torcida, tal como hacían los fabricantes con los maestros torcedores ${ }^{7}$.

Los torcedores de seda estaban organizados en una corporación gremial que hacia 1766 disponía de unos 300 maestros, con un número similar de oficiales. Antes de la supresión del colegio en 1793, tenían corrientes unos 112 tornos, que podían disponer de un máximo de 240 husos y eran accionados por fuerza de tracción animal (Díez, 1992, pp. 46-47). Según indicaba Lapayese, cada torno era atendido por dos operarios y podía torcer entre 10 y 14 libras de seda diarias (Lapayese, 1779, pp. 43 y 81). Aunque algunos de los maestros efectuaban la operación por su cuenta, adquiriendo la seda en madeja y vendiéndola posteriormente torcida a los fabricantes, la mayoría trabajaba por encargo al servicio de estos o de otros intermediarios o especuladores. De ahí la intensa conflictividad que existía con ellos, a los que acusaban de entregarles la seda húmeda y mezclada con todo tipo de ingredientes y exigirles su devolución seca y limpia, provocando una merma del peso que no era compensada por los desperdicios que aquellos les descontaban. Dicha merma se intensificaba al hallarse a su cargo el devanado de la seda, por lo que eran los más perjudicados por los fraudes que cometían las rodeteras. Lapayese llegaba a calcular que la reducción del peso de la materia prima que sufrían por ambas circunstancias podía llegar al $10 \%$, por lo que, considerando que un torno podía torcer 3.000 libras de seda al año, la pérdida que sufrían podía ascender a 300 libras, cuyo valor estimaba en 1.300 pesos (Lapayese, 1794, p. 48). Este problema se veía agudizado por la congelación de la remuneración que se les abonaba por la realización del torcido, que estaba fijada desde hacía tiempo en 6 sueldos por libra, mientras que ellos consideraban que debía ser superior a 8 , por lo que acusaban a los fabricantes de haber constituido un frente común para evitar su incremento (Díez, 1992, p. 49). Pero, para compensar estas pérdidas, los torcedores intensificaron los abusos que se cometían en la elaboración de la materia prima, agudizando el problema de la mala calidad que acababa teniendo la fibra de seda. Así, le añadían más aceite al que ya llevaba; no eliminaban las partículas de suciedad; cambiaban la seda recibida por otra de inferior calidad; o efectuaban el torcido con mucha mayor rapidez, por lo que resultaba defectuoso. Aunque algunos fabricantes trataron de solucionar el problema controlando directamente el torcido, se

Esta información se ha obtenido en el libro de deliberaciones de la compañía. Archivo del Colegio del Arte Mayor de la Seda de Valencia (en adelante A.C.A.M.S.V.), libro 21. Ver las deliberaciones de los años 1779-1782. El análisis de la actividad realizada por la Compañía se ha realizado en Franch, 1996. Sobre la remuneración obtenida por las mujeres en la escuela de hilaza de Albal, ver VV.AA., 1777, p. 59. 
enfrentaron inmediatamente con la celosa defensa de su privativa por parte del colegio de torcedores. Así, la Junta General de Comercio dispuso 1757 que los maestros del arte mayor de la seda no podían poseer tornos propios, salvo que hubiesen sido examinados por aquel colegio o pusiesen al frente de ellos a un maestro torcedor. Estas atribuciones fueron las que utilizaron también para oponerse desde el principio a los nuevos tornos que comenzaron a construirse en la fábrica de Vinalesa en 1769, aunque en esta ocasión su demanda no fue atendida al disponer la fábrica de un privilegio real que lo permitía. En ella se construyeron finalmente 22 tornos de torcer seda que tenían algo más del doble de husos que los tornos tradicionales, a pesar de lo cual eran atendidos también por dos operarios, y eran accionados por la fuerza de tracción hidráulica de la acequia de Moncada. De ellos, 21 torcían la seda pelo más fina y de mayor calidad, y podían elaborar al año unas 15.000 libras, mientras que el otro podía torcer una cantidad similar de seda trama (Lapayese, 1779, pp. 81 y 206-207).

Además de su oposición a estas innovaciones, los torcedores se enfrentaron también intensamente con los fabricantes en la década de 1770 para conseguir el incremento de la remuneración que percibían. Las cuentas del pósito que había creado el colegio del arte mayor de la seda para abastecer de materia prima a los maestros permiten comprobar que aquella dependía del tipo de seda que elaboraban, siendo más elevada en la medida en que la fibra tratada era más fina y delicada. Aunque se llegaban a pagar 13,5 sueldos por cada libra de «seda lisos», los tipos más comunes eran la seda hilandera, que se pagaba a 10 sueldos por libra; la seda hilandero, que se pagaba a 9 sueldos por libra; y la trama de mayor grosor, que se pagaba a 4 sueldos por libra. En los tres primeros casos, el torcedor tenía, además, un descuento del $4 \%$ de la materia prima recibida en concepto de «desperdicios», el cual se reducía al 3\% en el caso de la trama. Parece que en esta remuneración se incluía el devanado, ya que el propio colegió estimó también en 6 sueldos por libra el coste estricto del torcido cuando en 1771 realizó un presupuesto sobre los beneficios que podía obtener en la explotación de un torno que le había cedido la Junta de Comercio. Se trataba, en este caso, de un torno de 972 husos, es decir, cuatro veces más grande que los que utilizaban los torcedores. Al frente del mismo se puso a un maestro de este oficio que percibía una remuneración de dos libras diarias (unos 30 reales de vellón) en compensación de su trabajo y de la responsabilidad por la seda entregada. Estaba auxiliado, además, por 11 oficiales, algunos de los cuales cobraban 4 y otros 4,6 reales de vellón diarios. El coste total de la mano de obra ascendía a 7,5 libras diarias, a las

Sobre la oposición de los torcedores a la construcción de la fábrica de Vinalesa y el conflicto con los maestros del colegio del arte mayor de la seda en 1757, ver Archivo Municipal de Valencia (en adelante A.M.V), Tribunal de Comercio, año 1769, exp. nº 46. 
que se debía añadir una más por el mantenimiento de las tres caballerías que accionaban el torno y el aceite que se necesitaba para alumbrar la estancia. No obstante, el colegio consideraba que la remuneración del maestro se podía reducir a la mitad poniendo al frente del torno a un maestro terciopelero y que el número de oficiales se podía reducir a 8 o 9, con lo que el gasto diario bajaría a 6,5 libras. Como el torno podía torcer unas 34 libras diarias, el coste por libra se reducía a 3,8 sueldos en este último caso, o a 5 sueldos según la cuenta inicial, por lo que resultaba más rentable que los 6 sueldos que cobraban los torcedores por realizar dicha operación. A pesar de ello, la escasez y el elevado precio que alcanzó la seda como consecuencia de la mala cosecha que se obtuvo en dicho año frustró estas expectativas, y el colegio optó por la devolución del torno a finales de $1771^{9}$. Todo ello pone de manifiesto que el ejercicio de dicha actividad era mucho más complejo y arriesgado que lo que aquellos cálculos permitían suponer.

La presión que ejercieron los torcedores para lograr el aumento de su remuneración acabó surtiendo sus efectos a finales de la década de 1770, como permite comprobar la documentación existente sobre las actividades de la compañía de Nuestra Señora de los Desamparados. Se trataba de una época en la que la intensa subida que estaban experimentando los precios agudizaba la caída que sufría el salario real, ya que la remuneración de la mano de obra se mantenía al mismo nivel desde principios de la centuria. Pero, significativamente, fue entonces cuando los oficiales de la construcción de Valencia lograron incrementar su jornal diario desde los 8 sueldos que percibían con anterioridad hasta los 9 sueldos que cobraban a partir de 1774, elevándose a 10 en 1780 y alcanzando los 11 a finales de la centuria, lo que representaba un aumento del 37,5\% en el plazo de unas dos décadas. Con algo más de retraso, experimentaron también un ascenso un poco inferior, tanto en términos absolutos como relativos, los peones, cuyo jornal se elevó desde los 6 hasta los 8 sueldos (un 33\%), y los maestros del mismo sector, cuyo incremento fue de 10 a 12 sueldos (un 20\%). En el caso de los torcedores, fue la Real Fábrica de tejidos de seda establecida en Valencia por los cinco gremios mayores la que rompió el frente común que habían mantenido los fabricantes en 1777, elevando la remuneración 6 dineros por libra e incrementando la compensación en concepto de desperdicios un $0,5 \%$. Así lo pudo constatar la compañía de Nuestra Señora de los Desamparados, ya que a finales de abril de dicho año solo existían dos torcedores dispuestos a trabajar para

Esta información procede del libro de deliberaciones del colegio del arte mayor de la seda. A.C.A.M.S.V. Sig. 2.5.2., libro 5. El presupuesto sobre la rentabilidad del torno se realizó el 23 de julio de 1771, y el acuerdo para su devolución se adoptó el 22 de noviembre posterior. Por su parte, las cuentas del pósito del colegio, en las que consta la remuneración abonada a los torcedores, pueden verse en el mismo archivo. Sig. 3.6.4., legajo $n^{\circ} 10$. 
ella, y ambos solicitaron la aplicación de esas nuevas condiciones. No obstante, este fue solo el inicio de una sucesión posterior de pequeños incrementos que culminó el 25 de agosto de 1779, cuando se acordó abonar 12 sueldos por libra por el torcido de la seda hilandera; 11 sueldos por libra en el caso de la seda hilandero; y 6 sueldos por libra para la seda trama. En las dos primeras modalidades se incrementó también la compensación por desperdicios hasta el 5\%, fijándose en el $4 \%$ en la tercera de ellas ${ }^{10}$. Por tanto, en el plazo de dos años, la remuneración por la elaboración de la seda de mayor calidad se había incrementado alrededor de un 20\%, aumentándose un $25 \%$ adicional la compensación por desperdicios. Pero la subida fue superior en el caso de la seda de inferior calidad, que aumentó un 50 y un 33\% respectivamente.

En todo caso, el enfrentamiento de los fabricantes con los torcedores alcanzó en 1779 una de sus fases más agudas, que fue aprovechada por la compañía de Nuestra Señora de los Desamparados para romper el monopolio que ejercían sobre dicha actividad. Tratando de estimular la difusión del nuevo método de hilatura, la Junta General de Comercio requirió a la compañía que adquiriese 20 tornos similares a los de Lapayese, que se colocaron en el huerto de Datos, próximo a la ciudad, con el fin de elaborar en ellos la seda de la nueva cosecha. Pero, una vez iniciada esta, la compañía alegó que la calidad de la fibra obtenida se deterioraría al entregársela a los torcedores debido a los fraudes y abusos que estos cometían, por lo que solicitó autorización para efectuar directamente la operación en sus propios tornos. Su propuesta fue apoyada por la Junta de Comercio de Valencia, alegando la «...total oposición a la ylaza bajo el método Bocanson...» que había caracterizado al colegio de torcedores, así como «...la necesidad que los fabricantes han padecido y padecen por la falta del torcido, o bien por escasez de tornos o de operarios, pues teniendo sedas en madeja y no encontrar quien las torciese, han tenido que sufrir comprar torcido a precios mui excesivos...». De ahí que el intendente autorizase a la compañía a disponer de tornos propios el 20 de septiembre de $1779^{11}$. Se lograba, con ello, vulnerar las ordenanzas del colegio de torcedores, a diferencia de la tentativa anterior que se había realizado en 1757. Pero los cuatro tornos que la compañía puso en la casa de la Misericordia resultaron muy difíciles de gestionar directamente, por lo que a principios de 1782 decidió realizar una contrata para ceder su explotación integrando el devanado, tal como se hacía con los torcedores. A pesar de que ello ponía de manifiesto la complejidad de ambas operaciones, los fabricantes intensificaron su ofensiva en contra del colegio de torcedores, llegando a solicitar en 1786 que dicha

\footnotetext{
10 A.C.A.M.S.V., Sig. 2.3.1., libro 21. Ver las deliberaciones de los años 1777-1779. Sobre la evolución de los salarios de la construcción de la ciudad de Valencia, ver Palop, 1977, pp. 275-276.

11 A.C.A.M.S.V., Sig. 3.4.5., leg. 2, exp. $\mathrm{n}^{\circ} 4$.
} 
actividad fuera declarada «industria popular». Al situarse en la línea de la política económica que estaba manteniendo la monarquía, esta petición pudo contribuir a la emisión de la Real Cédula de 29 de enero de 1793 que disponía la supresión del colegio de torcedores de seda. Sin embargo, esta disposición no hizo más que agravar los abusos que se realizaban en el torcido de la seda y deteriorar aún más la calidad de la fibra obtenida. Así lo constataba el propio Lapayese en la memoria que realizó en 1794, en la que, aun reconociendo que había sido uno de los firmantes de la solicitud de 1786, consideraba que era necesario el restablecimiento del colegio de torcedores, procediendo solamente a la reforma de sus ordenanzas gremiales (Lapayese, 1794, pp. 54 y 76-82). La Junta de Comercio de Valencia se situó inicialmente también en esta línea, pero en 1811 llegó a proponer no solo el restablecimiento del colegio de torcedores, sino que sus miembros trabajasen «...con arreglo a las ordenanzas del año 1732 y sujeción a los sesenta y dos capítulos que contiene...» (Franch, 1986, pp. 208-209). Realmente, más que la vuelta al pasado, la solución de las deficiencias del torcido pasaba, al igual que en el caso de la hilatura, por el cambio del sistema de producción, creando establecimientos fabriles que introdujesen las innovaciones técnicas que lo permitían.

\section{La remuneración del trabajo en la elaboración de tejidos de seda}

La elaboración de los tejidos de seda era una actividad urbana que se hallaba regulada por las ordenanzas del colegio del arte mayor de la seda de Valencia. Esta corporación fue reforzada por la política mercantilista que se impulsó tras la finalización de la guerra de Sucesión, logrando extender su jurisdicción al conjunto del Reino de Valencia en las ordenanzas de 1722, aunque su aplicación efectiva solo se logró en las de 1736. La resistencia que plantearon los artesanos de las restantes localidades a su control por parte de la corporación de la capital del territorio condujo a la práctica desaparición de la actividad en la mayoría de ellas, dando lugar a su concentración en la ciudad de Valencia, que en la segunda mitad del siglo XVIII solía disponer del 93,5\% de los telares existentes en el conjunto del Reino de Valencia (Franch, 2000, pp. 46-52). Las medidas adoptadas en la primera mitad de la centuria para estimular el crecimiento manufacturero favorecieron la expansión del sector, incrementándose el número de telares desde los 800 que se consideraban existentes antes de 1720 hasta rondar los 3.500 a finales de la década de 1730. No obstante, a partir de mediados de la centuria su número se estabilizó, por lo que solo de forma excepcional se lograron superar los 3.800 telares con posterioridad (Martínez Santos, 1981, pp. 96 y 144). En cambio, el número de maestros del colegio del arte mayor de la seda siguió creciendo con relativa regularidad a lo largo de toda la centuria, pasando de los 413 existentes 
en 1715 a los 1.079 registrados en 1760 y alcanzando los 1.824 en 1800 . De ahí que la ratio de telares por maestro mejorase en la primera mitad de la centuria, pasando de 1,9 en 1715 a 3,5 en 1760, y volviese a retroceder posteriormente, situándose en 2,1 en 1797. Esta evolución refleja muy bien las dos fases que experimentó la sedería valenciana en el siglo XVIII, poniendo claramente de manifiesto que el periodo más dinámico de expansión se situó en la primera mitad de la centuria, generándose a partir de entonces intensos desequilibrios que contribuyeron a su decadencia posterior. Una imagen similar refleja el análisis de las otras dos categorías laborales de la corporación, puesto que si hacia 1740 existían 1.212 oficiales con una ratio de 1,6 por cada maestro, hacia 1780 aquellos habían ascendido a 1.646, pero la ratio se había reducido a 1,1 por maestro (Díez, 1990, p. 72). Realmente, frente al ritmo regular de ingreso de nuevos maestros, el de oficiales y aprendices tendió a reducirse en la segunda mitad de la centuria, bajando la ratio que suponían con respecto a la de aquellos de 1 a 0,4 en el primer caso y de 4,6 a 2,1 en el segundo (Franch, Navarro y Rosado, en prensa). Además de evidenciar las crecientes dificultades que afectaban al sector, esta evolución ponía de manifiesto el deterioro de las condiciones sociales que sufrían los maestros, los cuales estaban experimentando un intenso proceso de proletarización que dio lugar a que sus condiciones de trabajo se diferenciasen cada vez menos de las que tenían los miembros de las categorías inferiores de la jerarquía gremial. Pero el fenómeno no tuvo un carácter general, ya que una minoría de aquellos logró beneficiarse de la expansión manufacturera y protagonizó un espectacular enriquecimiento ejerciendo funciones de carácter empresarial. La polarización social de los maestros se puso ya claramente de manifiesto a mediados de la centuria. En el registro de oficiales que se realizó hacia 1740 consta que el 33\% de los maestros no disponía de ellos y que el $21 \%$ tenía solo uno, mientras que solo el $5 \%$ de los maestros disponía de más de 4 oficiales. En la contribución extraordinaria de 1741, el $83,5 \%$ de los maestros abonaron unas cuotas muy modestas, frente a una minoría del 5,4\% que pagó las sumas más elevadas, aportando el 29,3\% de la contribución total. Finalmente, en el registro de la bolla de 1753-54 solo figuraban 412 declarantes, frente al millar de maestros que existían entonces, y los 45 de ellos que manifestaron más de 5.000 varas acumulaban cerca del 60\% de la extensión total (Franch, 2014). La existencia de esta minoría ponía de manifiesto la considerable difusión que adquirió el «verlagssystem» en la sedería valenciana dieciochesca, la cual también se ha podido documentar en los registros de los telares activos de 1738 y 1771 (Franch, 1997). Según esta información, la mayoría de los telares trabajaba por cuenta de comerciantes o de otros maestros que ejercían funciones empresariales, reduciéndose incluso los que se hallaban en manos de artesanos que conservaban su independencia desde el 30 al 19\% ente ambas fechas. 


\section{Tabla 3. Remuneración estipulada en las ordenanzas de 1736 por cada vara que los maestros elaboraban para atender los encargos de los comerciantes, y que los oficiales confeccionaban en los talleres de aquellos (cantidades expresadas en sueldos por vara)}

\begin{tabular}{|c|c|c|c|}
\hline Modelo de tejido & $\begin{array}{c}\text { Comerciantes } \\
\text { a maestros } \\
\end{array}$ & $\begin{array}{c}\text { Maestros a } \\
\text { oficiales }\end{array}$ & $\begin{array}{c}\text { \% oficiales/ } \\
\text { maestros }\end{array}$ \\
\hline Fondo en raso cortado y realzado & 20 & 10 & 50,0 \\
\hline Felpa bordada en tela de tafetán & 20 & 10 & 50,0 \\
\hline Rizo terciopelado y felpa & 14 & 10 & 71,4 \\
\hline Felpa de media cuenta & 13 & 10 & 76,9 \\
\hline Damasco ordinario & 6,5 & 3 & 46,1 \\
\hline Brocatelo ordinario & 7 & 3 & 42,9 \\
\hline Raso negro & 9 & 3,5 & 38,9 \\
\hline Raso primavera de 2-3 lanzaderas no continuas & 9,5 & 4 & 42,1 \\
\hline Raso de primavera de 3 y 4 lanzaderas & 11,5 & 4,5 & 39,1 \\
\hline Raso de primavera de 4 lanzaderas continuas & 13 & 5 & 38,5 \\
\hline Raso liso de 132 portadas & 4,5 & 2,7 & 59,1 \\
\hline Raso liso de 120 portadas & 4 & 2,7 & 66,5 \\
\hline Raso liso de 108 portadas & 3,5 & 2 & 57,1 \\
\hline Media tela de 3 lanzaderas, 1 de plata y 2 de seda & 13 & 6 & 46,2 \\
\hline Media tela de 3 y 4 lanzaderas & 14 & 7 & 50,0 \\
\hline Tabí de plata para dar aguas & 6 & 4 & 66,7 \\
\hline Media tela alama atafetanado & 8 & 5 & 62,5 \\
\hline Restaño de plata & 10 & & \\
\hline Ormesí & 3 & 2 & 66,7 \\
\hline Burato de 2 lanzaderas & 2 & 2 & 100,0 \\
\hline Aldúcar & 2 & 1,3 & 66,5 \\
\hline Setinela de 63 portadas en 5 lisos & 4 & 2,5 & 62,5 \\
\hline Tafetán doble y entredoble & 2 & 1,3 & 66,5 \\
\hline Mantos de seda & 2 & 1,3 & 66,5 \\
\hline Tafetán ancho & 3 & 2 & 66,7 \\
\hline Chamelotón y teletón & 3 & 2 & 66,7 \\
\hline Riseta de 63 portadas de a 4 lisos & & 2 & \\
\hline Picote en cuenta de tafetán & & 1,7 & \\
\hline Cordellada & & 2 & \\
\hline Ferrandilla doble & & 2,7 & \\
\hline Ferrandilla sencilla & & 2 & \\
\hline Tercianela & & 2 & \\
\hline
\end{tabular}


Realmente, el «verlagssystem» tenía un carácter tan general que en las ordenanzas de 1736 se reguló tanto la remuneración que los maestros debían abonar a los oficiales como la que los mercaderes estaban obligados a pagar a los maestros. En la tabla 3 se han plasmado las tarifas estipuladas al respecto en los capítulos 81 y 82 de las citadas ordenanzas, en los cuales se especificaban 26 modelos de tejidos en el caso de los maestros y 31 en el de los oficiales ${ }^{12}$. Las remuneraciones más elevadas correspondían a los tejidos más ricos y pesados, como el fondo o la felpa, en cuya confección los maestros percibían hasta 20 sueldos por vara y los oficiales hasta 10 , por lo que su tarifa solía ser un 50\% inferior a la de aquellos. No obstante, la diferencia aún era superior en los tejidos labrados algo más ligeros, como los rasos de varias lanzaderas, el brocatel y el damasco, en cuya elaboración los oficiales recibían entre 3 y 5 sueldos por vara y los maestros entre 6,5 y 13, representando la remuneración de aquellos alrededor del $40 \%$ de la que percibían estos. Por el contrario, en el caso de los tejidos más simples y ligeros, como los rasos lisos o el tafetán, la diferencia entre ambas remuneraciones era inferior, ya que los maestros percibían entre 2 y 4,5 sueldos por vara y los oficiales entre 1,33 y 2,66, rondando su remuneración el $66 \%$ de la de aquellos. Por tanto, todo parece indicar que la mayor diferencia en la remuneración de ambos colectivos se producía cuando se procedía a la elaboración de los tejidos labrados que requerían una mayor cualificación de la mano de obra, atenuándose mucho cuando la simplicidad del género elaborado permitía su confección a los artesanos que disponían de menor pericia técnica. Se puede considerar, incluso, que los tejidos más simples, como la riseta, el picote, la cordellada, la ferrandilla o la tercianela, eran elaborados exclusivamente por los oficiales, ya que no se indica la tarifa a abonar a los maestros. Ahora bien, en los propios capítulos aludidos de las ordenanzas se precisaba que los modelos de tejido que se especificaban eran los más corrientes, por lo que se establecía que en el caso de que se encargase la confección de otros géneros y no se llegase a un acuerdo entre el comerciante y el maestro o entre este y su oficial sobre la remuneración a abonar, las partes debían acudir al arbitraje del colegio del arte mayor de la seda, el cual designaría a dos maestros expertos en la materia para que fijasen la tarifa correspondiente.

Los problemas de esta índole debieron ser cada vez más frecuentes, puesto que la tónica dominante en el siglo XVIII fue la proliferación de modelos de tejidos que variaban constantemente en función de la moda imperante en los centros de poder más influyentes de la Europa de la época, siendo los fabricantes franceses los que controlaban y estimulaban en mayor medida estas tendencias (Poni, 1993; Pérez, 2008). Así, en el registro de la bolla de 1753-54 figuran más de 80 modelos diferentes,

A.C.A.M.S.V., Sig. 3.1.1., exp., no 17. 
ninguno de los cuales representaba más del 16\% de la extensión total declarada. El más frecuente en este aspecto era la griseta, que era un tejido confeccionado con ligamento de tafetán estampado con pequeños dibujos de flores u otros motivos. Le seguía el damasco y el terciopelo, que era, no obstante, el tejido que representaba una mayor proporción de la materia prima total consumida (Franch, 2014). El análisis de la producción realizada por la Compañía de Nuestra Señora de los Desamparados entre 1774 y 1785 también pone de manifiesto que el tafetán era el tejido más frecuente, seguido del damasco, el raso y el terciopelo, que era el que representaba una proporción mayor del valor total de la producción realizada (Franch, 2000, p. 106). El libro de control de los fabricantes que llevaba esta compañía permite comprobar que la remuneración que se abonaba a los maestros se situaba en la línea de la estipulada por las ordenanzas de 1736, aunque con algunas variaciones que cabría atribuir a la introducción de modalidades diferentes de un tipo determinado de tejido. Así, en el caso del fondo, la remuneración era de entre 24 y 26 sueldos por vara, algo superior a la indicada en las ordenanzas; para el terciopelo era idéntica a la fijada para la felpa de media cuenta, es decir, 13 sueldos por vara; para el raso, el brocado y el tafetán era de 8 sueldos por vara, bastante superior a la allí estipulada, sobre todo en la última modalidad, que debía tener algunas características específicas; para el damasco, en cambio, era algo inferior, situándose en 6 sueldos por vara. En todos los casos, se abonaba al maestro, además, un cuarto de onza por cada libra de seda consumida, es decir, un $2,1 \%$ de la materia prima que se le había entregado para la confección del tejido. Se trataba de compensarles por las «juntas» o desperdicios que hubiesen sufrido en dicho proceso. Habitualmente, desde el momento en que se efectuaba el encargo, el maestro comenzaba a recibir una cantidad de dinero semanal, que solía ascender a 3 libras, como anticipo de la remuneración que debía percibir al finalizar la pieza confeccionada. Cuando se producía su entrega, se procedía a la liquidación de la cuenta, tanto de la seda suministrada con tal finalidad como del dinero recibido ${ }^{13}$. De ahí que resulte muy difícil conocer la remuneración diaria o anual que percibía habitualmente un maestro del colegio del arte mayor de la seda.

Sin embargo, la información global que proporcionó el colegio sobre la producción realizada en el año $1788^{14}$ nos permite disponer de algunas referencias para realizar una aproximación general al ritmo de trabajo y el valor anual de la remuneración obtenida. Como puede apreciarse en la tabla 4, existían entonces 3.542 telares, de los que solo 300 se hallaban parados. En aquellos trabajaban 5.764 hombres, que eran los que

A.C.A.M.S.V., Sig. 2.3.1., libro 7.

A.C.A.M.S.V., Sig. 2.5.3., libro 4, fol. 27. Esta información ya fue analizada desde el punto de vista de la estructura general de la manufactura en Franch, 2000, pp. 101-106. 
Tabla 4. Distribución de la producción valenciana de tejidos de seda en 1788 (extensión en varas y valor de su proceso de elaboración en reales de vellón)

\begin{tabular}{|l|c|c|c|c|c|c|c|c|c|}
\hline Tipo telar & $\begin{array}{c}\mathbf{N}^{\mathbf{0}} \\
\text { telares }\end{array}$ & $\mathbf{\%}$ & Operarios & Varas & $\mathbf{\%}$ & Valor & $\mathbf{\%}$ & $\begin{array}{c}\text { Varas/ } \\
\text { telar }\end{array}$ & $\begin{array}{c}\text { Valor/ } \\
\text { operarios }\end{array}$ \\
\hline Muestra & 1.098 & 31,0 & 2.496 & 718.720 & 31,5 & 4.312 .320 & 32,5 & 654,6 & $1.727,7$ \\
\hline Terciopelo & 920 & 25,9 & 1.284 & 220.800 & 9,7 & 2.208 .000 & 16,6 & 240,0 & $1.719,6$ \\
\hline Llano & 892 & 25,2 & 1.320 & 1.248 .800 & 54,8 & 3.746 .400 & 28,2 & $1.400,0$ & $2.838,2$ \\
\hline Fondo & 282 & 7,9 & 594 & 57.684 & 2,5 & 1.153 .680 & 8,7 & 204,6 & $1.942,2$ \\
\hline Angostos & 50 & 1,4 & 70 & 32.400 & 1,4 & 64.800 & 0,5 & 648,0 & 925,7 \\
\hline Parados & 300 & 8,5 & & & & & & & \\
\hline Mujeres & & & 2.000 & & & 1.800 .000 & 13,6 & & 900,0 \\
\hline Total & 3.542 & & 7.764 & 2.278 .404 & & 13.285 .200 & & 643,3 & $1.711,1$ \\
\hline
\end{tabular}

elaboraban los tejidos, y 2.000 mujeres, que se ocupaban de las labores previas de encañar y urdir la seda. Cada telar estaba atendido por algo más de un operario, salvo en el caso de los de muestra, en los que el tejedor necesitaba el auxilio de un tirador, y los de fondo, en los que se elaboraban los tejidos más ricos y pesados, por lo que en ambos casos la media solía ser algo superior a dos. Los telares de muestra, en los que se confeccionaban tejidos labrados, eran los más numerosos, representando una proporción similar tanto de la producción como del valor total del trabajo realizado, situándose alrededor del 31-32\%. La producción anual media que se obtenía en cada uno de ellos era de 654,6 varas, lo que, teniendo en cuenta que las jornadas laborales de un año podían oscilar entre 240 y 280, implicaría una producción media de alrededor de 2,5 varas diarias. Así mismo, cada operario obtenía una remuneración anual de $1.727,7$ reales de vellón, por lo que el jornal diario medio sería algo inferior a los 7 reales de vellón. Evidentemente, la cantidad percibida por cada uno de ellos sería diferente en función de la categoría laboral de que disponía y el tipo de trabajo que realizaba, pero estas diferencias no se han logrado precisar. Los telares de terciopelo y de fondo, en los que se confeccionaban los tejidos más ricos y pesados, tenían conjuntamente una entidad similar a la de los de muestra. No obstante, la producción que obtenían era muy inferior, representando solo el 12,2\% del total, lo que reflejaba la mayor lentitud del proceso de elaboración. De ahí que el valor del trabajo que requerían fuese superior, ascendiendo al 25,3\% del total. Todo ello determinaba que la producción anual media de cada telar se situase en 204,5 varas en el caso del fondo y 240 en el de terciopelo, lo que implicaría que la producción media se situaría en ambos casos ligeramente por debajo de 1 vara diaria. La remuneración media anual de cada operario era de 1.719,6 reales de vellón en esta última modalidad y de $1.942,2$ en aquella, por lo que el jornal diario medio sería algo superior a los 7 reales 
de vellón. Los telares de llano, en los que se confeccionaban los tejidos más simples y ligeros, representaban alrededor de la cuarta parte del total, pero proporcionaban algo más de la mitad de la producción total realizada, lo que ponía de manifiesto la mayor rapidez del proceso de confección. De hecho, en cada telar se podían elaborar unas 1.400 varas anuales, lo que implicaba una producción media de alrededor de 5 varas diarias. Aunque la proporción que representaba la remuneración obtenida sobre el valor total era muy inferior a la que suponía la de la extensión de los tejidos realizados, cada operario podía percibir anualmente unos 2.838,2 reales de vellón, lo que implicaría un jornal diario algo superior a los 10 reales. Los 50 telares angostos, en los que se elaboraban cintas, pañuelos y otros géneros menores, suponían una proporción muy reducida de las manufacturas realizadas. Aunque cada telar podía producir anualmente unas 648 varas, lo que implicaba un ritmo medio diario similar al obtenido en los telares de muestra, la remuneración obtenida por los operarios era muy inferior a la de los que trabajaban en los telares anchos, ya que ascendía a 925,7 reales de vellón anuales, lo que implicaría un jornal de unos 3,5 reales diarios. Una remuneración similar obtenían las 2.000 mujeres que realizaban las operaciones previas al tejido, ya que percibían anualmente una media de 900 reales de vellón. Realmente, descontando el valor de estos dos últimos colectivos, los 5.694 operarios que trabajaban en los telares anchos obtenían una remuneración media anual de 2.005,7 reales de vellón. Se trata de una cantidad significativamente similar a la que indicaba Tomás Pérez Estala para los tejedores de paños segovianos en su dictamen de 1803, quien indicaba que los dos operarios que trabajan en cada telar ganaban en conjunto 4.000 reales anuales, los que, repartidos entre los 280 días de trabajo útiles que calculaba al año, «...les resulta a siete reales de jornal en cada uno...» (Franch, 1991, p. 128). Aplicando este mismo criterio, el jornal medio diario de aquellos 5.694 operarios sería de 7,2 reales de vellón, que podrían elevarse hasta 8,3 reduciendo las jornadas laborales a 240, como indicaba Galabert en la fábrica de Vinalesa.

Profundizar más allá de estas cifras medias resulta muy difícil, ya que, al tratarse de una remuneración a destajo, variaba considerablemente en función de múltiples factores, como las dimensiones del taller artesanal, el tipo de tejido elaborado, la disponibilidad de materia prima, el ritmo de la producción, la categoría laboral, etc. La documentación de la compañía de Nuestra Señora de los Desamparados refleja muy bien tanto la complejidad del negocio como la diversidad de la casuística que podía plantearse. Su análisis permite comprobar las presiones que realizaron las mujeres a finales de la década de 1770 para incrementar la remuneración que percibían por el trabajo de encañar la seda, que se realizaba también a destajo. El 10 de marzo de 1779 la junta de dirección de la sociedad acordó aumentar en 6 dineros por libra la tarifa que se les pagaba, considerando que muchos fabricantes ya habían adoptado esta 
decisión, por lo que resultaba difícil encontrar mujeres dispuestas a trabajar al precio anterior. En consecuencia, la nueva tarifa quedaba en 3 sueldos por libra para la seda de color, y 2,5 sueldos por libra para la seda negra. Al reducirse la demanda de trabajo como consecuencia de la guerra, la compañía trató de rebajar el precio a mediados de 1780, volviendo a fijar en 2 sueldos el precio de la seda negra, y en 2,5 sueldos la de los colores finos y comunes, y manteniendo en 3 sueldos la de color verde, azul y pulga. No obstante, al comprobar que los restantes fabricantes mantenían las tarifas anteriores, se decidió anular este último acuerdo ${ }^{15}$. Con respecto a los maestros que trabajaban para la compañía, los libros de control que esta llevaba al efecto permiten comprobar que en sus mejores años llegaron a ser unos 50 . No obstante, su ritmo de trabajo era muy desigual, lo que podía obedecer a que dedicaban parte de su actividad a trabajar también por cuenta propia o por encargo de otro empresario sedero. Significativamente, en 1778, por ejemplo, fueron un total de 23 los que elaboraron para la compañía menos de 400 varas. Los que realizaron una producción que se podría considerar adecuada para disponer de un telar, comprendida entre 400 y 1.500 varas, fueron 18. Finalmente, hubo 8 que elaboraron más de 1.500 varas, por lo que debían regir un taller con varios telares. Con el fin de comprobar el ritmo de trabajo, se han seguido las operaciones realizadas con uno de ellos que parecía trabajar con cierta normalidad: se trata de Esteban Barduzal, que elaboraba exclusivamente damascos y que entre el 8 de agosto de 1775 y el 9 de agosto de 1776 produjo 893,7 varas. Habitualmente, transcurrían algo más de 50 días entre la entrega de la materia prima y la devolución del tejido elaborado, produciendo en este periodo alrededor de 130 varas. Si consideramos que los días laborables podrían ser algo más de dos tercios del total, el ritmo de producción diario podría situarse en 3,7 varas por día. Este ritmo se mantuvo de forma relativamente constante a lo largo de todo el año, salvo en el mes de julio de 1776, en que retrocedió a 2,6 varas, tal vez al escasear la seda de la cosecha anterior y no hallarse aún disponible la de la nueva. En todo caso, los registros de telares han puesto de manifiesto la existencia de un ciclo estacional de este tipo, ya que el número de los que se hallaban parados solía ser más elevado cuando aquellos se realizaban en los meses próximos a la cosecha (Franch, 2000, p. 99) ${ }^{16}$.

A pesar de esta diversidad de situaciones, existen algunos testimonios que revelan que el ritmo medio de trabajo solía ser bastante similar al que hemos obtenido

A.C.A.M.S.V., Sig. 2.3.1., libro 21. Ver las deliberaciones de los años 1779 y 1780 .

Sobre el seguimiento de la producción realizada para la Compañía de Nuestra Señora de los Desamparados por Estaban Barduzal, ver A.C.A.M.S.V., Sig. 2.3.1., libro 7. El número de maestros que trabajaban para la compañía se ha obtenido a partir del análisis de los libros diarios de fábrica. Sig. 2.3.2., libro 1. Sobre los acuerdos adoptados respecto a la remuneración del encañado de la seda, ver el libro de deliberaciones de la compañía. Sig. 2.3.1., libro 21. 
a partir de fuentes diversas. Así, Lapayese consideraba que los fabricantes estaban acostumbrados a hacer "...quatro varas de damasco de jornal...», aunque la mala calidad de la fibra de seda estaba reduciendo el ritmo en los últimos años e incrementando, por el contrario, la materia prima que debían utilizar para la reparar los cabos que se rompían, lo que se conocía como las «juntas» o «desperdicios» (Lapayese, 1779, p. 10). Por su parte, en 1811 el colegio del arte mayor de la seda procedió a la estimación de las ganancias de un tejedor con el fin de proporcionar la información necesaria para la formación del nuevo padrón de riqueza que se estaba confeccionando $^{17}$. Sus cálculos se basaban en la premisa de que un telar de terciopelo producía una vara diaria, mientras que uno de paño o raso podía elaborar tres varas. A pesar de su finalidad fiscal, esta información parece bastante verosímil, siendo en el cálculo de días laborables anuales y en los gastos que generaba la actividad donde se trató de rebajar los ingresos medios que podría obtener un maestro. Admitiendo la validez de dicho ritmo y la remuneración por vara que allí se indicaba, se podría afirmar que un maestro podría obtener elaborando terciopelo un jornal diario de 14 sueldos, mientras que el salario del oficial que se estipulaba en las ordenanzas para este tipo de tejido era de 10 sueldos. Con respecto al raso, las ganancias diarias de un maestro podían ser de 18 sueldos, mientras que el oficial podía obtener entre 8 y 10 sueldos. Como la remuneración que la compañía de Nuestra Señora de los Desamparados abonaba a los maestros por la elaboración del damasco era bastante similar a la del raso, se puede estimar que las ganancias de ambas categorías artesanales serían similares en este tipo de tejido si se mantenía una producción diaria de tres varas, elevándose a 24 sueldos para los maestros y 12 sueldos para los oficiales en el caso de producir las cuatro varas que indicaba Lapayese. A partir de esta información se puede estimar que el salario más habitual de un oficial podía rondar los 10 sueldos diarios, por lo que sería muy similar al que percibía a finales de la centuria un trabajador de su misma categoría en la construcción. Los maestros podían tener unos ingresos más variables en función del tipo de tejido elaborado, pero, descartando el valor más elevado que hemos obtenido, tal vez oscilasen entre los 14 y 18 sueldos diarios, por lo que eran superiores a los 10,5 que podía percibir a finales de la centuria un trabajador de su misma cualificación en la construcción ${ }^{18}$. En la estimación realizada por el colegio

A.C.A.M.S.V., Sig. 2.5.4., libro 1, fols. 18-19.

Según los datos proporcionados por Palop, tanto los maestros como los oficiales de la construcción percibían un salario de alrededor de 10,5 sueldos diarios en la década de 1790 (Palop, 1977, pp. 275-276), lo que equivalía a 7,9 reales de vellón o 9,5 gramos de plata. Este salario era similar al de los albañiles de Castilla la Nueva, pero inferior a los cerca de 14 gramos de plata que percibía la misma categoría laboral en Barcelona. En el caso de los maestros albañiles, la distancia era aún mayor, ya que en Castilla la Nueva se situaba en torno a los 14,5 gramos de plata, y en Barcelona rondaba los 18 (Feliu, 1991, pp. 97 y 103). Esta última remuneración, que equivalía a unos 15 
con fines fiscales en 1811, se trató de reducir su entidad deduciendo los gastos que comportaba la actividad, entre los cuales se incluían incluso 12 libras anuales por el alquiler de la casa en la que tenían el telar. En todo caso, aquellos eran algo más elevados en la elaboración del raso que en la del terciopelo, lo que podría atenuar la superior remuneración que se obtenía en la producción del primero. Pero las ganancias anuales de los maestros se trataron de rebajar, sobre todo, computando solamente 180 días laborables. En estas condiciones, los ingresos netos de un maestro solo rondaban las 90 libras, es decir, alrededor de 1.350 reales de vellón, por lo que se concluía que «...no quedando quatro reales diarios, no podrá dar de comer a su muger y demás familia...». Ciertamente, la situación podía ser menos dramática incrementando el número de jornadas laborales a entre 240 y 280 , como se ha indicado anteriormente. Pero la grave crisis que estaba experimentando la sedería valenciana desde finales de la década de 1780 y la práctica paralización de la actividad que comportaron las guerras revolucionarias y la posterior invasión napoleónica repercutieron negativamente sobre las condiciones laborales de la mayoría de los artesanos, lo que incrementaría considerablemente validez de dicha estimación en ese periodo en concreto.

\section{Conclusión}

El sistema de producción tradicional utilizado en la hilatura de la seda valenciana durante el siglo XVIII condicionaba intensamente el ritmo de trabajo y la remuneración obtenida por la mano de obra ocupada en el sector, determinando la calidad de la fibra finalmente obtenida y repercutiendo incluso en las fases ulteriores del proceso de producción. La necesidad que tenían los cosecheros de proceder rápidamente a la enajenación de su producción, junto con los afanes especulativos de los intermediarios que les compraban los capullos «por granjería», determinaban que el proceso se realizase con rapidez, acentuando el carácter estacional que tenía la cosecha de seda. La operación se realizaba, básicamente, en los dos o tres meses posteriores a ésta, procediéndose a la contratación de una mano de obra relativamente especializada que percibía una remuneración muy elevada. El jornal de las hilanderas era un 50\% más

reales de vellón, solo era percibida por dos de los operarios de la construcción que trabajaban en las obras del puerto de Valencia en 1797 (un maestro albañil y un capataz de albañiles). Aparte de ellos, existían otros 23 albañiles más cualificados que percibían entre 7 y 8,5 reales de vellón, siendo su salario medio de 7,7 reales, es decir, unos 10,3 sueldos, por lo que podrían considerarse como oficiales y tendrían una remuneración similar a los trabajadores de su misma categoría en la elaboración de tejidos de seda. El grueso de la mano de obra del sector de la construcción que trabajaba en las obras del puerto eran 78 amasadores y 18 peones que percibían 5 reales de vellón diarios; 163 peones que cobraban 4,5 reales; y otros 21 peones con un salario de 4 reales. A.M.V., Documentación Lonja, caja 56, exp. $\mathrm{n}^{\circ} 19$. Esta información ha sido analizada con mayor detalle en Franch, 2007, pp. 192-194. 
elevado que el que percibían los peones del sector de la construcción, mientras que los hilanderos podían percibir un salario similar al de los oficiales o maestros de este sector. Pero, además, ambos estaban auxiliados por un ayudante de su mismo sexo que percibía alrededor de la tercera parte de su salario, y a la remuneración de todos ellos se debía añadir la manutención, que representaba entre el 40 y el 50\% del coste total de la mano de obra. Las modalidades de contratación eran muy diversas, dependiendo el coste de la mano de obra de la calidad de la fibra elaborada, la modalidad del ajuste acordado (a jornal o a destajo), y la inclusión o no de la alimentación de los trabajadores contratados. La más ventajosa para los cosecheros e intermediarios era la contratación de hilanderos para elaborar trama a destajo sin abonarles la alimentación. Esto es lo que explica que, a pesar de su reiterada prohibición alegando los efectos negativos que ocasionaba en la calidad de la fibra obtenida, se siguiese recurriendo con mucha frecuencia a la utilización de esta modalidad de contratación. Por su parte, el salario femenino era alrededor de un $45 \%$ inferior al masculino de la misma categoría laboral, siendo esta mano de obra la que se solía utilizar para la elaboración de la fibra de mayor calidad. Ambas circunstancias son las que explican que se recurriese exclusivamente a ella en los establecimientos fabriles en los que se procedió a la aplicación de los nuevos métodos de producción utilizados en las áreas más avanzadas de la Europa de la época. Pero, además, su remuneración se redujo considerablemente, bajándose un 33\% en el caso de las hilanderas y un $12 \%$ en el de sus ayudantes y no incluyéndose la alimentación. En conjunto, la reducción salarial experimentada suponía un $63,5 \%$, implicando un descenso del coste de la mano de obra sobre cada libra de seda producida de entre el 30 y el $40 \%$. Junto con la utilización exclusiva de mano de obra femenina, la disminución del salario fue facilitada por la reducción de la estacionalidad del proceso de producción, utilizándose nuevos métodos para proceder al ahogado del capullo, lo que permitió abonar los jornales percibidos por los trabajadores menos cualificados. Pero, aun así, la estacionalidad no desapareció completamente, reduciéndose la actividad en los meses más fríos y húmedos del invierno tanto por motivos climáticos como por la escasez de la materia prima en los meses más alejados de la cosecha.

Ambas circunstancias afectaban también a las fases ulteriores del proceso de producción. El devanado de la seda era realizado fundamentalmente por mano de obra femenina, que trabajaba a tiempo parcial en sus propios domicilios. La irregularidad de su ritmo de producción generaba problemas puntuales de escasez de materia prima que repercutían en detrimento de los torcedores. Así mismo, los fraudes que cometían para incrementar sus ganancias empeoraban la calidad de la seda que devanaban. De ahí las considerables ventajas que comportaba la concentración y mecanización de esta actividad. Con los métodos de producción tradicionales, su control 
se solía dejar en manos de los torcedores, quienes se quejaban de las molestias y perjuicios que ello les ocasionaba y reclamaban su segregación en las contratas que realizaban con los fabricantes. Aunque la remuneración de las rodeteras se realizaba a destajo, su jornal diario podía rondar los dos reales de vellón, que era similar al obtenido por las mujeres que trabajaban en las «escuelas patrióticas» creadas a partir de mediados de la década de 1770 o al de las auxiliares de las hilanderas de la fábrica de Vinalesa. En todo caso, junto con la segregación del control de esta actividad, los torcedores emprendieron en dicha década una ofensiva para lograr el incremento de la remuneración que les abonaban los fabricantes por el devanado y el torcido de la seda. Su entidad dependía de la calidad de la fibra elaborada, e incluía un descuento de entre el 3 y el $4 \%$ de la materia prima recibida en concepto de los «desperdicios» que se derivaban del proceso. La presión ejercida dio lugar a que a finales de la década de 1770 la remuneración se elevase entre un 20 y un 50\%, en función de la calidad de la fibra elaborada, aumentándose la compensación por «desperdicios» entre un 25 y un $33 \%$ dependiendo de dicho criterio. Esta circunstancia, junto con los abusos que realizaban para incrementar sus ganancias, la estricta defensa de su facultad privativa en el ejercicio de la actividad ante las tentativas de los fabricantes de disponer de sus propios tornos, y la oposición que presentaron a la introducción de los nuevos procedimientos de hilatura y torcido siguiendo el método de Vaucanson, contribuyó al descrédito de la corporación artesanal que regulaba la actividad y condujo a la supresión del colegio de torcedores de seda en 1793.

Por su parte, la elaboración de tejidos de seda experimentó un intenso crecimiento en la Valencia del siglo XVIII, aunque a partir de mediados de la centuria la cifra de los telares existentes aumentó a un ritmo menor que el número de maestros registrados en la corporación gremial que controlaba la actividad. A su vez, estos crecieron más que los oficiales y aprendices que contrataban, lo que refleja el deterioro de las condiciones sociales que estaban conociendo. Realmente, la mayoría de ellos trabajan por encargo de comerciantes o artesanos enriquecidos, siendo muy pocos los maestros que lograron mantener su independencia económica a finales de la centuria. En las propias ordenanzas de 1736 se reguló la remuneración que éstos debían percibir de los empresarios que les contrataban, la cual dependía del tipo de tejidos que elaboraban y se diferenciaba más de la que ellos mismos debían pagar a sus oficiales en el caso de los modelos más ricos y pesados y, sobre todo, de los más complejos que requerían una mayor cualificación. A partir de la información disponible sobre la producción realizada en 1788 se ha podido constatar que la mano de obra femenina constituía alrededor de la cuarta parte de los operarios que trabajaban directamente en la elaboración de los tejidos de seda, percibiendo un salario medio inferior en un $55 \%$ al de los artesanos ocupados en los telares anchos. Estos percibían una media de 
alrededor de 2.000 reales de vellón anuales, lo que, en función del número de jornadas laborales que se atribuyan a cada anualidad, podía suponer entre 7 y 8 reales de vellón diarios. Pero su entidad concreta dependía de la categoría laboral del artesano, siendo los oficiales los que rondaban los 7 reales de vellón, mientras que los maestros podían percibir entre 11 y 15 reales, dependiendo del tipo de tejido que elaboraban. El jornal de aquellos era bastante parecido al de los trabajadores de su misma cualificación en el sector de la construcción, mientras que el de estos lo superaba claramente, pudiendo equipararse solamente al de los maestros o capataces de albañilería que ejercían la máxima responsabilidad en las obras de mayor magnitud, como es el caso de la construcción del puerto de Valencia. No obstante, el número de jornadas laborales anuales dependía en gran medida, en el caso de la industria de la seda, de la disponibilidad de la materia prima, por lo que se veía condicionado por el ciclo estacional que experimentaba su producción. Los registros de telares disponibles han puesto de manifiesto que el número de los que se hallaban parados se incrementaba en los meses más alejados de la cosecha, e incluso en los más inmediatos a ésta, ya que la nueva materia prima debía ser sometida a las fases previas del proceso de producción de los tejidos de seda. Los artesanos fueron muy conscientes de esta debilidad, que trataron de paliar mediante la creación de un pósito que les permitiese disponer de un abastecimiento regular de aquella o a través de la constitución de grandes compañías por acciones que les facilitasen una mayor continuidad en el trabajo que realizaban. Resulta significativo, en este sentido, que la Compañía de Nuestra Señora de los Desamparados se crease en 1772, tras la pésima cosecha del año anterior, que había dado lugar a que en febrero de dicho año se hallasen parados el 67,7\% de los telares existentes (Franch, 1996, pp. 559-560). A finales de la centuria, la crisis que experimentó el sector se convirtió en un factor adicional que provocaba la paralización de las fábricas, lo que impulsó a las élites y las instituciones valencianas a la adopción de numerosas iniciativas de carácter benéfico con el fin de paliar la miseria de los artesanos (Martínez Santos, 1981, pp. 147-159). 


\section{Bibliografía citada:}

Allen, Robert C. (2001) «The great divergence in European wages and prices from the middle ages to the first world war», Explorations in Economic History, 38, pp. 411-447. http://dx.doi.org/10.1006/exeh.2001.0775

Andrés, José Ignacio y LANZA, Ramón (2014), «Prices and real wages in Seventeenth Century Madrid», Economic History Review, 67, pp. 607-626. http://dx.doi. org/10.1111/1468-0289.12047

CAvanilles, Antonio José (1958), Observaciones sobre la historia natural, geografía, agricultura, población y frutos del Reyno de Valencia, Zaragoza, Instituto Elcano, Departamento de Geografía Aplicada.

CHor, Davin (2005), «Institutions, wages and inequality: The case of Europe and its periphery (1500-1899)», Explorations in Economic History, 42, pp. 547-566. http://dx.doi.org/10.1016/j.eeh.2005.02.004

Díez, Fernando (1990), Viles y mecánicos. Trabajo y sociedad en la Valencia preindustrial, Valencia, Institució Alfons el Magnànim.

DíEz, Fernando (1992), «La crisis gremial y los problemas de la sedería valenciana (finales del siglo XVIII y principios del siglo XIX)», Revista de Historia Económica, año X, no 1, pp. 39-61. http://dx.doi.org/10.1017/ S0212610900003220

Feliu, Gaspar (1991), Precios y salarios en la Cataluña moderna, Madrid, Banco de España.

Franch, Ricardo (1986), Crecimiento comercial y enriquecimiento burgués en la Valencia del siglo XVIII, Valencia, Institució Alfons el Magnànim.

FrANCH, Ricardo (1990), «La comercialización de la seda valenciana a finales del Antiguo Régimen: el "contraste” de la ciudad de Valencia», Revista de Historia Económica, año VIII, n 2, pp. 271-304.

FrANCH, Ricardo (1991), «Ganadería, exportación de lanas e industria pañera al final del Antiguo Régimen: el dictamen de Tomás Pérez en 1803», Cuadernos de investigación histórica, $\mathrm{n}^{\mathrm{o}} 14, \mathrm{pp} .107-133$.

Franch, Ricardo (1996), «Los negocios de una gran empresa sedera en la Valencia del siglo XVIII: La compañía de Nuestra Señora de los Desamparados», Revista de Historia Económica, año XIV, nº 3, pp. 557-589.

FrANCH, Ricardo (1997), «Artesanado sedero y capital comercial en la Valencia del siglo XVIII», Hispania. Revista Española de Historia, nº 195, pp. 93-114.

FRANCH, Ricardo (2000), La sedería valenciana y el reformismo borbónico, Valencia, Institució Alfons el Magnànim.

FrANCH, Ricardo (2004), «El cultivo de la morera y las iniciativas para la mejora de la hilatura y el torcido de la seda en el siglo XVIII. El carácter pionero de la 
fábrica de Vinalesa», en VV.AA., Actes del Segon Congrés d'estudis de l'Horta Nord, Valencia, Ajuntament de Vinalesa, pp. 19-45.

FrANCH, Ricardo (2007), «La fase inicial de construcción del puerto a finales del Antiguo Régimen», en Hermosilla, Jorge (ed.), Historia del puerto de Valencia, Valencia, Facultat de Geografia i Història, Universitat de València, pp.184-203. Franch, Ricardo (2014), «La diferenciación social del artesanado y el control empresarial del negocio sedero en la Valencia de mediados del siglo XVIII», en Franch, Ricardo, Andrés, Fernando y Benítez, Rafael (eds.), Cambios y resistencias sociales en la Edad Moderna. Un análisis comparativo entre el centro y la periferia mediterránea de la Monarquía Hispánica, Madrid, Sílex, pp. 63-72.

Franch, Ricardo, MuÑoz, Daniel y Rosado, Luis (en prensa), «La reproducción de los maestros y la transformación de las condiciones sociales de los miembros del colegio del arte mayor de la seda de Valencia en el siglo XVIII», Revista de Historia Industrial.

García SAnz, Ángel (1986), Desarrollo y crisis del Antiguo Régimen en Castilla la Vieja. Economía y sociedad en tierras de Segovia de 1500 a 1814, Madrid, Akal. GonZÁlez Enciso, Agustín (1980), Estado e industria en el siglo XVIII: la fábrica de Guadalajara, Madrid, Fundación Universitaria Española.

Hamilton, Earl J. (1975), El tesoro americano y la revolución de los precios en España, 1501-1650, Barcelona, Ariel.

Hamilton, Earl J. (1988), Guerra y precios en España, 1650-1800, Madrid, Alianza. LAPAYESE, José (1779), Tratado del arte de hilar, devanar, doblar y torcer las sedas según el método de Mr. Vaucanson, con algunas adiciones y correcciones a él. Principio y progresos de la fábrica de Vinalesa, en el Reyno de Valencia, establecida baxo la protección de S.M., Madrid, Blas Román.

LAPAYESE, José (1794), «Memoria sobre el hilado y torcido de la seda, leída en la Real Sociedad Económica de Valencia por Don Joseph de Lapayese, su autor y socio de mérito, aprobada y publicada por el mismo Real Cuerpo», en VV.AA., Consideraciones sobre el hilado y torcido de la seda de la Real Sociedad Económica de Valencia, Valencia, Hermanos de Orga, pp. 13-92.

Llopis, Enrique y GarcíA, Héctor (2011), «Precios y salarios en Madrid, 16801800», Investigaciones de Historia Económica, 7, pp. 295-309. http://dx.doi. org/10.1016/j.ihe.2010.10.002

Martínez SAntos, Vicente (1981), Cara y cruz de la sedería valenciana (siglos XVIII-XIX), Valencia, Institució Alfons el Magnànim.

Ortells y Gombau, Francisco (1783), Disertación descriptiva de la hilaza de la seda según el antiguo método de hilar y el nuevo llamado de Vocanson, Valencia, Joseph y Thomás de Orga. 
Palop Ramos, José Miguel (1977), Fluctuaciones de precios y abastecimiento en la Valencia del siglo XVIII, Valencia, Institució Alfons el Magnànim.

PÉREZ, Liliane (2008), «Inventing in a world of guilds: silk fabrics in eighteenthcentury Lyon», en Epstein, S. R. y Prak, M. (eds.), Guilds, Innovation and the European economy, 1400-1800, Cambridge, Cambridge University Press, pp. 232-263.

Poni, Carlo (1976), «All'origine del sistema di fabrica: Tecnologia e organizzazione produttiva dei mulini da seta nell'Italia settentrionale (se. XVII-XVIII)», Rivista Storica Italiana, Nápoles, pp. 444-497.

Poni, Carlo (1993), «Moda e innovazione: le strategie dei mercante di seta di Lione nel secolo XVIII», en Cavaciocchi, Simonetta (ed.), La seta in Europa. Secc. XIII-XX. Atti della «Ventiquattresima Settimana di Studi», Prato, Le Monnier, pp. 17-55.

SARASÚA, Carmen (2008), «Technical innovations at the service of cheaper labor in pre-industrial Europe. The Enlightened agenda to transform the gender división of labor in silk manufacturing», History and Technology, vol. 24, $\mathrm{n}^{\circ}$ 1, pp. 2339. http://dx.doi.org/10.1080/07341510701616865

Sonenscher, Michael (1996), «Trabajo y salario en el París del siglo XVIII», en López, Victoria y Nieto, José Antonio (eds.), El trabajo en la encrucijada. Artesanos urbanos en la Europa moderna, Madrid, Libros de la Catarata.

SolÀ, Àngels (2010), «Silk technology in Spain, 1683-1800. Technological transfer and improvements», en History of technology. Volume Thirty, Londres, Bloomsbury Publishing, p. 111-120.

VAn Zanden, Jan L. (1999), "Wages and the standard of living in Europe, 15001800», European Review of Economic History, 2, pp. 175-197. http://dx.doi. org/10.1017/S136149169900009X

Vasumathi, B.V. (2000), An analytical study of the silk reeling operations in Karnataka, Indian Institute of Science.

VV.AA. (1777), Instituciones Económicas de la Sociedad de Amigos del País de la ciudad i Reino de Valencia, Valencia, Benito Monfort.

VV.AA. (1794), Consideraciones sobre el hilado y torcido de la seda de la Real Sociedad Económica de Valencia, Valencia, Hermanos de Orga. 